Article

\title{
Assessment of Cities' Adaptation to Climate Change and Its Relationship with Urbanization in China
}

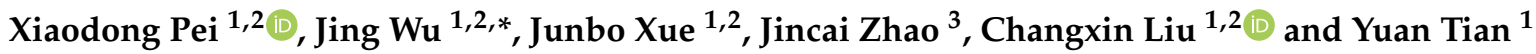 \\ 1 Institutes of Science and Development, Chinese Academy of Sciences, Beijing 100190, China; \\ xdpeiucas@126.com (X.P.); jbxue@casisd.cn (J.X.); liuchangxin@casisd.cn (C.L.); tianyuan0307@126.com (Y.T.) \\ 2 School of Public Policy and Management, University of Chinese Academy of Sciences, Beijing 100049, China \\ 3 School of Business, Henan Normal University, Xinxiang 453007, China; zhaojincai1989@163.com \\ * Correspondence: wujing@casisd.cn
}

Citation: Pei, X.; Wu, J.; Xue, J.; Zhao, J.; Liu, C.; Tian, Y. Assessment of Cities' Adaptation to Climate Change and Its Relationship with Urbanization in China. Sustainability 2022, 14, 2184. https://doi.org/ $10.3390 /$ su14042184

Academic Editor: Adriana Del Borghi

Received: 14 December 2021 Accepted: 11 February 2022 Published: 15 February 2022

Publisher's Note: MDPI stays neutral with regard to jurisdictional claims in published maps and institutional affiliations.

Copyright: (C) 2022 by the authors. Licensee MDPI, Basel, Switzerland. This article is an open access article distributed under the terms and conditions of the Creative Commons Attribution (CC BY) license (https:// creativecommons.org/licenses/by/ $4.0 /)$.

\begin{abstract}
Global climate change has led to more frequent occurrences of extreme, dangerous events; therefore, it is urgent to enhance cities' adaptation to climate change. Focusing on the impact of high temperature, low temperature, drought, and flooding, we established multi-dimensional assessment systems covering natural, economic, and social elements for cities' climate change adaptations. Based on the assessment systems, studies on adaptation to climate change were conducted in 248 cities in China using the entropy weight method, coefficient of variation method, and exploratory spatial data analysis; with the help of geographically weighted regression (GWR), the relationships between four types of urbanization and cities' adaptation to climate events were explored. The results showed the following: (1) High-administrative-level cities had higher adaptation than ordinary prefecture-level cities. (2) The differences in adaptation to the four types of climate events between cities within each of the seven regions in China presented significantly different spatial patterns. (3) Under the four types of climate events, the global spatial correlations of cities' adaptations in China were positive. The agglomeration characteristics of adaptation were mainly H-H and L-L agglomerations. (4) When analyzing the impacts of four types of urbanization on cities' adaptation to climate events, the fitting effects of GWR models were far better than those of OLS models. Population urbanization, economic urbanization, land urbanization, and industrial urbanization had different impacts on adaptation. Under the influence of social and economic development, the urbanization regression coefficients of different cities had significant spatial differences.
\end{abstract}

Keywords: adaptation; assessment system; climate change; GWR model; urbanization

\section{Introduction}

Since the Industrial Revolution, the amount of GHGs in the atmosphere has been rising, and the global climate is now changing at an unprecedented rate. According to the IPCC Sixth Assessment Report [1], the global surface temperature was $1.09{ }^{\circ} \mathrm{C}$ higher in 2011-2020 compared with that in 1850-1900. Climate warming has caused glacial retreat, rising sea levels, ocean acidification, imbalance of water resource distribution, and serious adverse effects on natural ecosystems and biodiversity. Meanwhile, with the increasing frequency, impact scope, and degree of damage from extreme weather events, people's lives and property have suffered heavy losses, and the sustainable development of the socioeconomic system is also facing severe challenges. Cities, as the main gathering place for human activities, occupy just $2 \%$ of the Earth's land but account for more than $60 \%$ of energy consumption and $75 \%$ of carbon emissions [2]. As regions with a high risk of global climate change disasters, cities have also become the main battlefield of the human response to climate change and deserve more attention.

In terms of coping with climate change, the formulation of countermeasures has changed from prevention and mitigation in the 1970s and mitigation in the 1980s to adaptation, which is widely accepted today [3]. Adaptation, which first originated in ecology, is 
now widely used in climate research and has become one of the core concepts of global change science. In the field of climate change, different scholars have different conceptualizations or definitions of adaptation according to their academic background or research objects [4-7], but all of them emphasize the adjustment of systems to reduce vulnerability and enhance coping capacity in the face of adverse climate change impacts. Research on adaptation to climate change is diverse but mainly focuses on two aspects: (1) policy formulation and framework design and (2) quantitative analysis of adaptation. These two aspects complement each other. On the one hand, policy formulation and framework design can provide methodological guidance and mechanism guarantees for climate change adaptation assessment. On the other hand, the results of the quantitative analysis of adaptation are conducive to dynamic improvement in policy and the refinement of frameworks.

Policy formulation and framework design: Constructing long-term mechanisms for adaptation to climate change and formulating adaptation strategies or frameworks are the most common means for governments to carry out climate change adaptation actions, which can provide guidance for countries or regions in defining overall adaptation goals and are also an important prerequisite for climate risk monitoring and adaptation assessment. According to different national conditions, some countries have issued separate "adaptation frameworks" or "national adaptation plans" to guide practice, while others have issued action plans that match the strategies. For example, the relevant departments of climate change adaptation in Japan have issued corresponding strategies, plans, guides, etc. In academia, such research includes the following: based on the evaluation of the effectiveness and benefit of the adaptation measures of related projects, the UNDP designed a comprehensive monitoring and evaluation framework for climate change adaptation, which is suitable for research at various scales [8]; Brink et al. [9] proposed an analytical framework of urban ecosystem adaptation based on the relationships between climate change adaptation, ecosystem services, and sustainability theories; Kuang et al. [10] proposed a decision-making assessment tool for climate change impacts by discussing the framework of adaptation assessment and management of international rivers under climate change; and Aguiar et al. [11] investigated 147 local adaptation policies in Europe and found that the main obstacles that needed to be overcome to promote the formulation and implementation of climate adaptation plans are insufficient resources, lack of capacity, unreliable commitments, and uncertain risks.

Quantitative analysis of adaptation: By establishing the monitoring and assessment mechanisms, systematically collecting data on climate change and its risks, understanding the level of socioeconomic readiness for potential climate change impacts, and scientifically assessing the changing trends of climate change risks and the status quo of adaptation in various fields, which is conducive to accurately guiding the practice of climate change adaptation, we can improve the pertinence and effectiveness of national adaptation measures. The practices of major countries in climate change adaptation monitoring and assessment can be summarized as follows: first, carrying out climate change risk monitoring, such as climate change risk assessment and the identification of priority adaptation areas; second, regularly evaluating the implementation progress and effects of adaptation work, including conducting annual assessments of adaptation to climate change in accordance with the laws and regulations, and establishing annual reporting systems for adaptation to climate change; and third, researching and developing scientific monitoring and evaluation systems that are applicable to the actual situations. In academia, such research includes Araya-Munoz et al. [12], who constructed an indicator system from the three aspects of awareness, capacity, and action to evaluate the adaptation to climate change in the Concepción metropolitan area in Chile and found that the adaptability of all cities had improved significantly from 1992 to 2002, but the relative differences between cities had not changed significantly. Zhao et al. [13] combined the SPRR model and the IPCC assessment framework to establish an exposure-sensitivity-resilience indicator system and evaluated the adaptation capacity of 12 urban agglomerations in China by using set-pair analysis; they found that the adaptation level of different regions varied greatly and the 
level of economic development played a key role. Bachner et al. [14] proposed a general modeling framework to comprehensively analyze how public adaptation to climate change affects the federal budget and found that it could have substantial positive macroeconomic effects on GDP, welfare, and employment. Cupać et al. [15] conducted a cost-benefit analysis of the proposed climate change adaptation measures in Bosnia and Herzegovina and explored their feasibility. Huang-Lachmann et al. [16] conducted an empirical study on 63 cities through multi-factor analysis and a logistic regression model, which showed that the climate change adaptation plan had a positive impact on the economic opportunities of cities.

Against the background of human sustainable development, the close relationship between climate change and urbanization has been widely considered. Many studies [17-21] showed that, in the process of urbanization, the rising energy consumption and land-use changes increase GHGs emissions and then exacerbate climate change. Some studies focused on the relationship between urbanization and climate change vulnerability [22-25]. For example, the SREX report [26] found with high confidence that urbanization along with settlement patterns and changes in socioeconomic conditions have all influenced observed trends in risk and vulnerability to climate extremes. Nowadays, the mainstream perspective in the literature tends to focus on urbanization as a driver of climate change and urban vulnerability, and few studies have explored the relationship between urbanization and climate change adaptation. In fact, urbanization is likely to have both positive and negative consequences for the overall adaptive capacity of cities and regions [27]. Applying the urban environment transitional model, researchers found that although wealthy cities in the Global North generate large amounts of GHG emissions, urbanization and urban economic growth have made them rich enough to develop adaptive systems to counteract the adverse effects of climate change [28,29]. Urbanization can also offer opportunities for disaster risk management, which can be the main driving force to enhance the ability to cope with climate change [30]. However, most of the urbanization defined in the above literature is based on "population," while, in fact, urbanization is a multi-dimensional process with rich connotations [31], including population, economy, land, and industry. The dynamic changes in these aspects may have very strong impacts on cities' adaptations to climate change. Therefore, it is necessary to deeply explore the relationships between various types of urbanization and cities' adaptations to climate change, which is beneficial for city managers to scientifically carry out urban planning and climate governance.

As one of the most vulnerable countries to climate change and extreme events in the world, China's policies and actions to adapt to climate change are still at the initial stage [32]. With the gradual advancement of China's climate change adaptation actions, it is urgent to carry out a large-scale and quantitative assessment of adaptation to climate change at the city level. China has a large number of cities with different geographical conditions and climate backgrounds and, therefore, these cities differ in the types and occurrence probabilities of climate events they face. Meanwhile, since the implementation of the economic reform in late 1978, China has experienced rapid economic growth and urbanization [33,34], and there are great disparities in the urbanization process between China's cities, which make the mechanisms and impact degrees of urban adaptation to climate change different. Considering the fact that the existing research mainly focuses on the evaluation of urban adaptation in some regions of China, or mainly investigated urban adaptation to climate change only from a social dimension, the comprehensive evaluation of urban adaptability still needs to be further developed. In addition, the mechanism of urbanization affecting climate change adaptation is not fully explored. Therefore, this study explored cities' adaptations to climate change in China to make up for the shortcomings of the existing literature. First, by focusing on the four most common climate events in China, namely, high temperature, low temperature, drought, and flooding, this study constructed comprehensive assessment systems covering natural, economic, and social factors to assess cities' adaptations to climate change and discusses the spatial patterns of adaptation. Second, we expanded the impact factors of cities' adaptations to climate change. 
Specifically, differing from the common selection of urbanization indicators based on the population mentioned above, this study explored the impact direction and magnitude on adaptation from the perspective of different types of urbanization. This part of the research is an important complement to the existing literature on cities' adaptation to climate change. The above two aspects are the important innovation points of this study, which are different from previous studies.

Section 2 introduces the study area and data sources, which also includes the research methods. The analysis results are shown in Sections 3 and 4 . Section 5 presents the conclusions and implications.

The research results have certain guiding significance and reference values for the development of climate change adaptation assessment methods in cities and the formulation of adaptation policies tailored to local conditions.

\section{Data and Methods}

\subsection{Study Area and Data Sources}

In this study, we chose 248 cities in China as the research objects: 4 municipalities, 5 state-plan cities, 27 provincial capital cities, and 212 ordinary prefecture-level cities. Cities in Hong Kong, Macau, and Taiwan were excluded from this study due to the limitation of data availability. As shown in Figure 1, these cities are distributed in seven major regions of China, with the total population and GDP accounting for $83.30 \%$ and $92.92 \%$ of the whole country, respectively. In addition, they have differences in social, economic, cultural, and climate conditions, with the average population ranging from 0.25 to 30.75 million. Therefore, the exploration results of these cities can represent the overall pattern of the whole country.

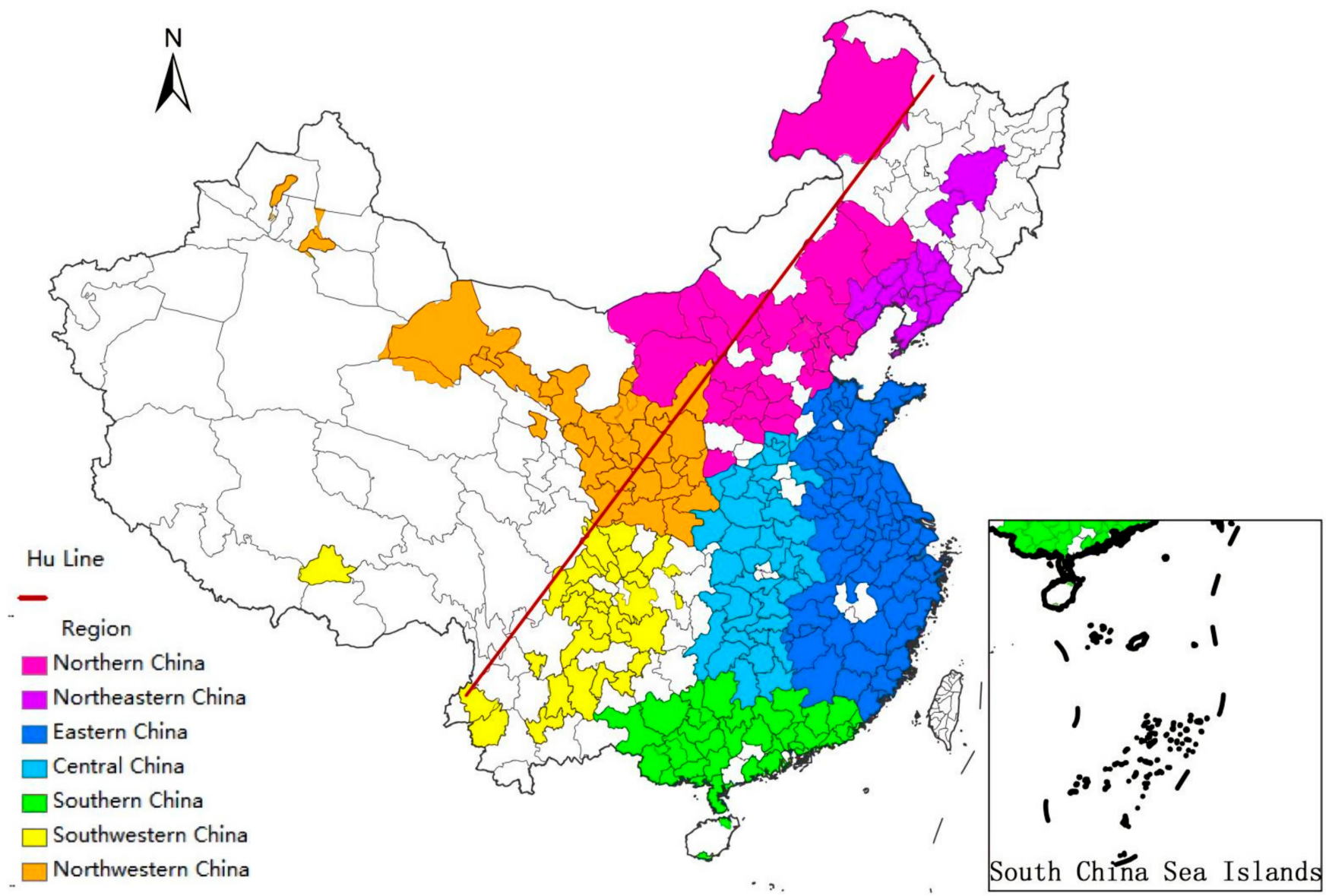

Figure 1. Regional distributions of 248 Chinese cities. 
The data used in the research were mainly from 2017. The population, economic, and social data (infrastructures, patents, etc.) involved in this study were mainly obtained from the Sixth Population Census of various cities, China City Statistical Yearbook 2018, China Real Estate Information, and Everbright Securities Research Report; the meteorological data were derived from China Meteorological Data Service Centre, which was obtained by spatial interpolation of meteorological station observation data. For some missing parts of the data, statistical methods, such as data fitting and forecasting, were used or searching through the Internet to supplement them. For details, see Appendix A.

\subsection{The Framework}

The purpose of this study was to conduct a comprehensive assessment of cities' adaptation to climate change, determine the differences of adaptation in different cities and regions, and explore the impacts of urbanization on adaptation. Based on the previous literature research, combined with the actual situation in China, this study constructed indicator systems, collected and standardized the data required for each dimension, determined the weight of each indicator by the entropy weight method, calculated the values of cities' adaptation to climate change by weighted comprehensive evaluation method, classified the cities and analyzed the spatial distribution features of adaptation based on spatial econometric approaches, and finally explored the role of urbanization in cities' adaptation to climate change using a GWR model. Based on the research ideas depicted in Figure 2, the main research methods of each step are introduced below.

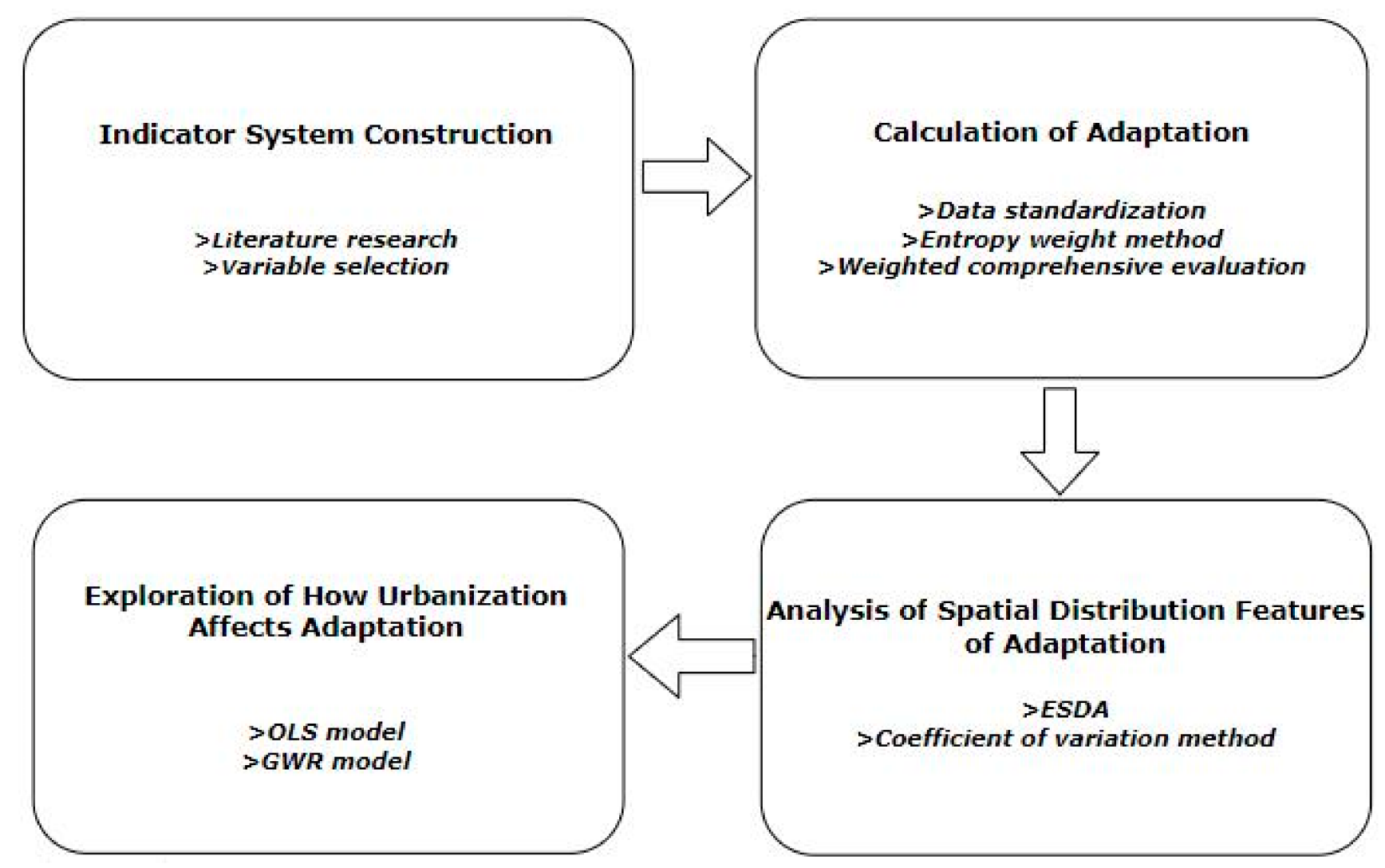

Figure 2. Research ideas and technical routes.

\subsection{The Assessment Indicator System}

Referring to the climate adaptation assessment framework [35,36] established by the Notre Dame Global Adaptation Initiative (ND-GAIN) and considering the actual situation in China and the availability of data, a three-level structural assessment indicator system for cities' adaptations to high temperature, low temperature, drought, and flooding was 
constructed in this study. The ND-GAIN climate adaptation assessment indicator system consists of two dimensions: vulnerability assessment and readiness assessment. Compared with IPCC's indicator system [37], ND-GAIN adds a readiness assessment, which can make the system more comprehensively reflect cities' adaptation characteristics, and the framework is now widely used in adaptation studies [38-40].

Vulnerability reflects the sensitive reaction and self-recovery ability of the research object to the disturbance of climate events in a specific space-time environment, which is composed of exposure, sensitivity, and adaptive capacity; readiness, which is composed of social readiness, governance readiness, and economic readiness, reflects the defense characteristics of the research object to the disturbance of climate events in a complex society-economy system and the capacity of it to mobilize adaptation investments from private sectors and to target investments more effectively. The adaptation indicators under different climate events are different to reflect the impact characteristics of each event, as shown in Appendix A.

\subsection{Entropy Weight Method}

The key step of assessing cities' adaptation to climate change is to determine the weight of indicators. As an objective assignment method, the entropy weight method is more scientific and reliable than subjective methods since it determines the weight of each indicator according to the difference in data disorder degree. If the indicator information entropy is smaller, it means that the indicator has a higher disorder degree and greater range of change; therefore, it has a greater impact on the comprehensive assessment. See Liu et al. [41] for the specific calculation formula.

After calculating the weight $w_{j}$ of each indicator using the entropy weight method, the adaptation assessment model was constructed based on the weighted comprehensive evaluation method that is commonly used in multiple indicators assessment, and the degree of adaptation is expressed by the adaptation score. The specific assessment model is

$$
A I i=\sum_{j}^{n} w_{j} Y_{i j}
$$

where $A I i$ is the adaptation score of city $i$. The calculation methods of vulnerability $V I$ and readiness $R I$ are the same as that of adaptation, but the indicator sets are different.

\subsection{Coefficient of Variation Method}

The coefficient of variation can objectively reflect the degree of difference within a set of data and avoid the deviation effect of absolute difference. Compared with range, variance, standard deviation, and other statistical indicators, it has the advantage of more accurately reflecting the degree of data dispersion. From a regional perspective, this study used the coefficient of variation to explore the unbalanced state of the internal adaptation differences in each region. The calculation formula is

$$
C V_{i}=\frac{1}{\overline{x_{i}}} \sqrt{\frac{1}{n-1} \sum_{j=1}^{n i}\left(x_{i j}-\bar{x}_{i}\right)^{2}}
$$

where $C V_{i}$ is the coefficient of variation of region $i, n i$ is the number of research units in region $i, x_{i j}$ is the adaptation value of research unit $j$ in region $i$, and $\overline{x_{i}}$ is the average value of all research units in region $i$.

\subsection{Exploratory Spatial Data Analysis}

Exploratory spatial data analysis (ESDA) is the collection of a series of spatial data analysis methods and techniques with the measurement of spatial association as the core, through description and visualization of the spatial distribution pattern of things or phenomena, to discover spatial agglomeration and anomalies to reveal the mechanism of 
spatial interactions among research objects. The common methods are Moran's I index and Moran's scatter plot.

Moran's I index ranges from -1 to 1 . A value greater than 0 indicates a positive spatial correlation, and the larger the value is, the stronger the spatial aggregation is. By contrast, a value less than 0 is a negative spatial correlation and the smaller the value is, the stronger the spatial difference is. A value equal to 0 is irrelevant, i.e., the spatial units are randomly distributed. See Moran and Ap [42] for the specific calculation. Moran's scatter plot can further explore the differences in adaptation to climate change between cities from a spatial perspective, which is divided into four quadrants corresponding to four types of local spatial association between a city and its cities: $\mathrm{H}-\mathrm{H}$ (quadrant I in the upper-right) indicates a city with a high value surrounded by cities with high values, L-H (quadrant II in the upper-left) indicates a city with a low value surrounded by cities with high values, L-L (quadrant III in the lower-left) indicates a city with a low value surrounded by cities with low values; H-L (quadrant IV in the lower right) indicates a city with a high value surrounded by cities with low values. H-H and L-L (respectively, L-H and H-L) refer to positive (respectively, negative) spatial autocorrelation, which indicates spatial clustering of similar (respectively, dissimilar) values.

\subsection{Geographically Weighted Regression Model}

In contemporary research, regression analysis is often used to explain influencing factors. The geographically weighted regression model (GWR), proposed by Brunsdon et al. in 1996 [43], is an extended local regression model based on the classical multiple linear regression model (OLS), which considers the spatial characteristics of observation indicators, and can explore the non-stationarity of spatial relations according to the change in parameter estimation values with geographical location and the spatial differentiation characteristics of the influence of various factors on explanatory variables in the study area. By using this method, the results are more realistic and accurate. Based on these advantages, the GWR model has been widely used in many fields, such as geography, economics, ecology, environmental science, and epidemiology. For example, Benedict [44] used the GWR to study the relationship between gambling behavior and the distribution of non-entertainment gambling machines in a New Zealand island; Lianjun Zhang et al. [45] found that the traditional linear or nonlinear models ignored the spatial variations when studying the tree diameter-height relationships, where the GWR model performed significantly better; and Fanglin Su [46] conducted an empirical study on China's R\&D knowledge spillovers at the provincial level, finding that GWR was superior to OLS in estimating the parameters of R\&D knowledge production.

The model can be shown as

$$
y_{i}=\beta_{0}\left(u_{i}, v_{i}\right)+\sum_{k} \beta_{k}\left(u_{i}, v_{i}\right) x_{i k}+\varepsilon_{i}
$$

where $y_{i}$ are the dependent variables, $x_{i k}$ are the independent variables, $\left(u_{i}, v_{i}\right)$ is the geographic coordinate of sample spatial unit $i, \beta_{0}\left(u_{i}, v_{i}\right)$ are the intercept terms, $\beta_{k}\left(u_{i}, v_{i}\right)$ are the regression coefficients, $k$ is the number of independent variables, and $\varepsilon_{i}$ are the error terms.

\section{Spatial Pattern Analysis of Adaptation}

\subsection{Perspective of Cities' Administrative Level}

Based on the calculation results of adaptation to climate change of 248 cities, it was found that the average adaptation scores of each type of climate event in highadministrative-level (HAL) cities (municipalities, state-plan cities, provincial capital cities) were higher than those of ordinary prefecture-level (OPL) cities, and the average vulnerability scores were lower and the average readiness scores were higher, as shown in Table 1. In fact, high-administrative-level cities were more advantageous in adapting to climate change because of their advanced economic development level, superior social security 
system, and mature governance institution. When setting up high-administrative-level cities, China fully takes into account the climatic conditions, resource endowments, and location conditions of the candidate cities, and the cities with a lower risk of being affected by disasters are more likely to be selected. In addition to the ability to attract large amounts of investment and financing in the field of climate, these cities are more likely to be favored by national policies and financial support [47].

Table 1. AI, VI, and RI scores of HAL and OPL cities.

\begin{tabular}{ccccccc}
\hline \multirow{2}{*}{ Climate Events } & \multicolumn{2}{c}{ AI } & \multicolumn{2}{c}{ VI } & \multicolumn{2}{c}{ RI } \\
\cline { 2 - 7 } & HAL & OPL & HAL & OPL & HAL & OPL \\
& Cities & Cities & Cities & Cities & Cities & Cities \\
\hline High Temperature & 0.6015 & 0.5009 & 0.4008 & 0.3522 & 0.2007 & 0.1488 \\
Low Temperature & 0.6141 & 0.5254 & 0.4131 & 0.3766 & 0.2010 & 0.1488 \\
Drought & 0.5829 & 0.4825 & 0.3294 & 0.2950 & 0.2535 & 0.1876 \\
Flooding & 0.5558 & 0.4847 & 0.3753 & 0.3508 & 0.1805 & 0.1339 \\
\hline
\end{tabular}

A higher VI indicates a lower vulnerability. All the data in the table passed the nonparametric test of independent samples, indicating that there were significant differences between the two groups of cities.

\subsection{Perspective of Regions}

According to the coefficient of variation formula, the degree of difference of adaptation to climate change within each of the seven major regions of China was calculated, as shown in Figure 3. As can be seen from the figure, the high-temperature (low-temperature) adaptation gap between cities showed an overall decreasing spatial pattern from south to north. The coefficients of variation for high- and low-temperature adaptations in southern China were the largest, reaching 0.142517 and 0.115093 , respectively, indicating that there was a large difference in the high-temperature (low-temperature) adaptation between cities within the region, and the adaptation ability was extremely uneven. Comparatively speaking, the internal differences in Northeastern China were the smallest, showing a good and balanced adaptation ability. The overall spatial pattern of the drought adaptation gap among cities decreased from west to east, with the largest coefficient of variation in Southwestern China and the smallest in Eastern China, but the differences in coefficients of variation between regions were not significant, indicating that the adaptation gap between cities within each of the regions showed a similar pattern. In addition, the coefficient of variation of adaptation to flooding was still the largest in Southwestern China and the smallest in Northeastern China. Comparing the four sub-figures, Southern China and Southwestern China need to be focused on the following: cities within the former face uneven adaptation to high temperature, low temperature, and flooding, and cities within the latter face uneven adaptation to high temperature, drought, and flooding, indicating that the adaptation gaps of cities within each of the two regions were very significant. The high-adaptation cities should provide technology, experience, and knowledge of adaptation to low-adaptation cities. Meanwhile, higher-level administrative units should strengthen financial and policy support to cities with low adaptation to enhance their readiness.

The coefficient of variation only reflected the gaps between cities within each of the regions. In addition, the adaptation gaps between regions were also worth exploring. The average adaptation scores of cities covered by each region were used to represent the regional score as shown in Figure 4 . The scores of adaptation to high temperature, low temperature, and flooding in Northern China, Northeastern China, and Northwestern China were always ranked in the top three of the seven regions, and the scores of adaptation to low temperature and flooding in Northwestern China were the highest. The top two regions of adapting to drought were Eastern China and Southern China. The scores of adaptation to high temperature and flooding were the lowest in Southern China, and the scores of adaptation to low temperature and drought were the lowest in Southwestern China. To some extent, this suggests that the north had a broader advantage in adapting to climate change and climate events compared with the southern regions of China. Meanwhile, the 
score ranges for the adaptation to climate events in seven major regions were high temperature 0.1245 , low temperature 0.0375 , drought 0.0657 , and flooding 0.0808 . The range of adaptation to high temperature was 3.32 times that of low temperature, which indicated that there was a small gap in adaptation to low temperature between regions, but there was a significant gap in high temperature. The key to promoting balanced adaptation to climate change in all regions of China lies in narrowing the gap of adaptation to high temperature.
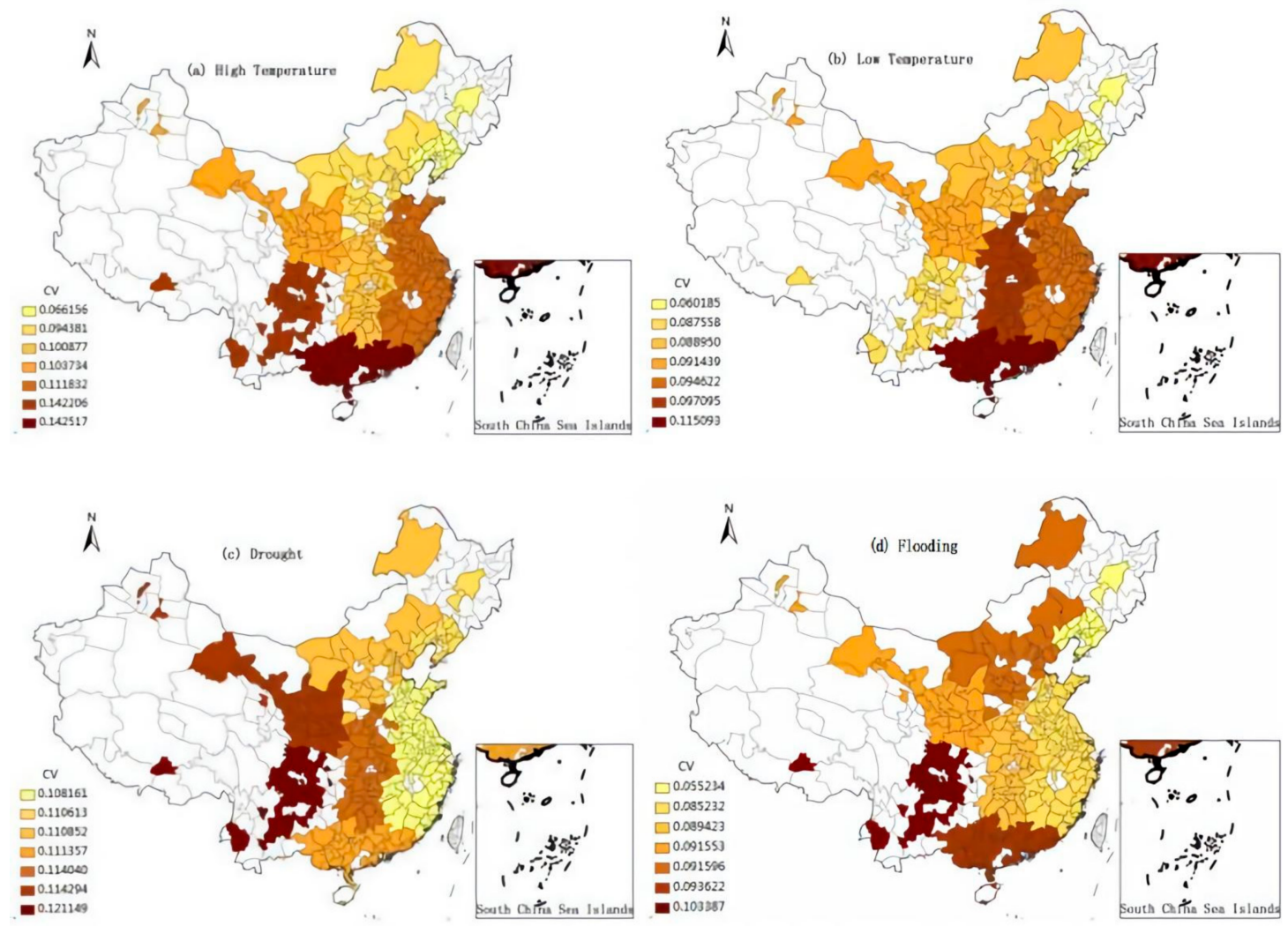

Figure 3. Spatial pattern of adaptation from the regional perspective (coefficient of variation).

\subsection{Spatial Distribution Pattern at Cities Level}

Adaptation analysis from the regional perspective only reflected the macro spatial distribution pattern. In order to more accurately explore the characteristics of cities' adaptation and carry out climate policies based on cities' conditions, it was necessary to conduct analysis and discussion at the city level, as shown in Figure 5.

High temperature: The overall pattern can be described as high in the north and low in the south. High-level cities were mainly concentrated in the three northeastern provinces (i.e., Heilongjiang, Jilin, and Liaoning), Inner Mongolia, Shandong, and the Beijing-TianjinHebei region. Medium-level cities were mainly distributed in Eastern China, Southwestern China, and the vast areas north of the Huaihe River-Qinling Mountain Line. In addition, some cities in southern Shaanxi near the Huaihe River-Qinling Mountain Line and some in Hunan and Hubei were also in this level. Low-level cities were mainly located in Guangdong, Guangxi, Sichuan, Chongqing, Henan, and the Eastern China region. In addition, it can be observed from the figure that the vast majority of coastal cities were in medium and high levels of adaptation. Most of the coastal cities are economically developed [48,49], and they belong to a maritime climate; therefore, the infrastructures are better, and it is usually cooler and more humid. 

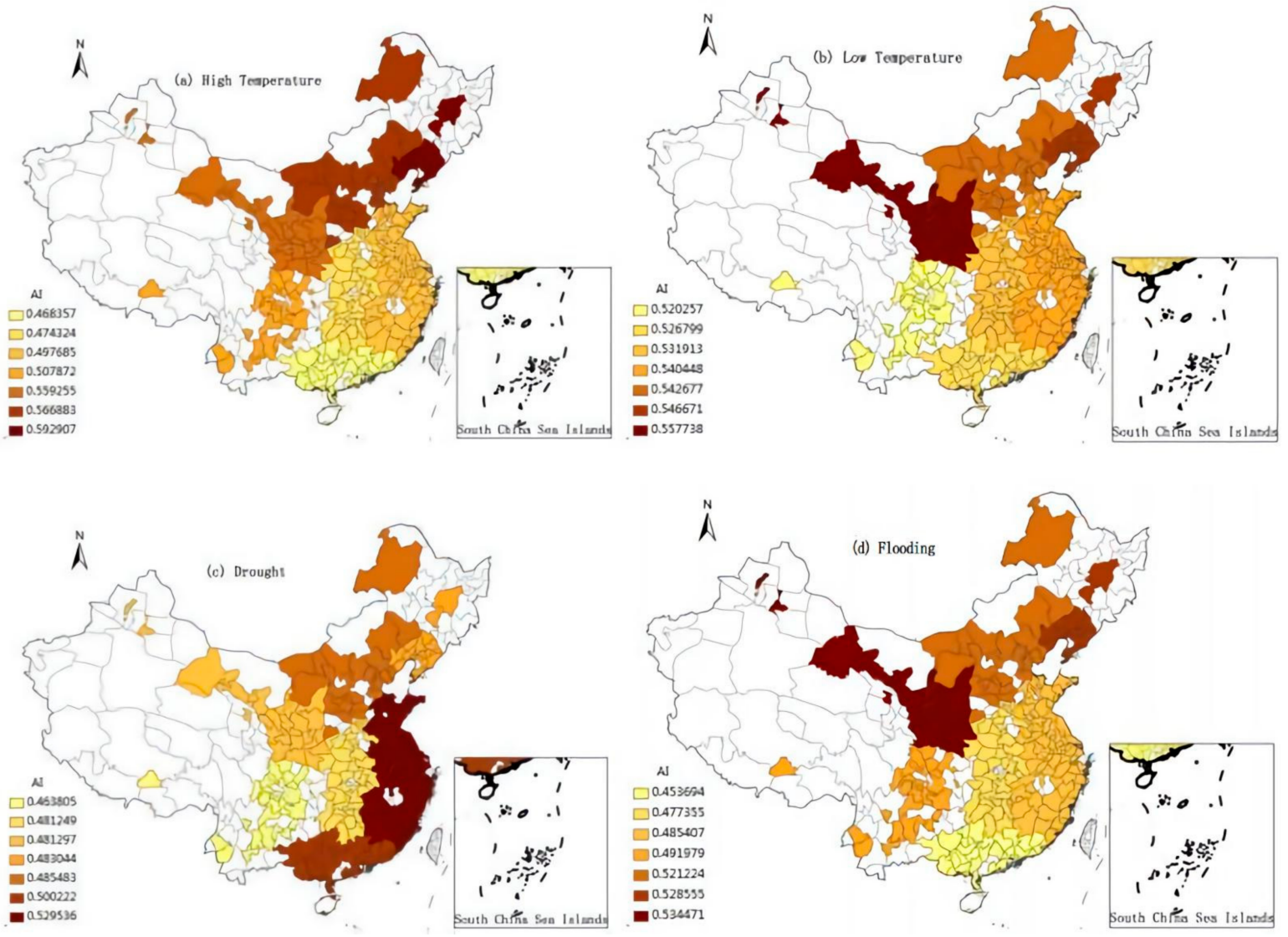

Figure 4. Spatial pattern of adaptation from the regional perspective (adaptation index).

Low temperature: Most of the high-level cities were at the high-administrative level and were widely distributed, but scattered in spots. Both medium-level and low-level cities formed a relatively obvious agglomeration. The former were mainly located in Eastern China, Northwestern China, the three northeastern provinces, and Inner Mongolia, which was due to the improvement in adaptation ability to low temperature by heating in winter in these areas [50]. Relatively speaking, cities located in Southwestern China, the Huaihe River Basin, and Central China were less adaptable.

Drought: Cities' adaptation showed an obvious decreasing trend from southeast to northwest, forming significant agglomeration characteristics. The Jiangsu-Zhejiang-Anhui region and the Pearl River Delta region presented two high-level clusters. In addition, Fuzhou, Quanzhou, and Xiamen in Fujian Province were also cities of high-level adaptation to drought. Furthermore, the medium-level cities were mainly concentrated in the southeast coastal areas and the Pearl River Basin. The majority of cities located in China's Second Ladder showed low adaptation characteristics to drought, especially Northwestern China, which had significant agglomeration characteristics.

Flooding: The spatial clustering characteristics of adaptation to flooding were also very prominent, especially in the Pearl River Basin, the Huaihe River Basin, Hunan, and Jiangxi, where the large hydrographic networks, copious rainfall, and low-lying flat terrain make them face greater risks [51,52]. From south to north, the adaptation gradually increased, and the cities with high adaptation ability were mainly distributed in Inner Mongolia, the three northeast provinces, and the northwest area of Gansu Province. 
As shown in Table 2, there were 50 cities with low adaptation under the four types of climate events, which indicated that these cities are facing greater climate risks, and it is urgent to carry out research and development and the integration and promotion of adaptation technology to effectively improve their adaptation levels. These cities account for $20.16 \%$ of the study sample, covering a population of 230.901 million, mainly distributed in the southern region of China. Hunan, Hubei, Anhui, Henan, Guangdong, Sichuan, and Guangxi contain a large number of the above-mentioned cities, affecting more than 20 million people. To advance the construction of adaptation ability to a higher level, it is extremely necessary to coordinate the work of adaptation to climate change, strengthen communication and exchanges, and deepen cooperation actively among cities.
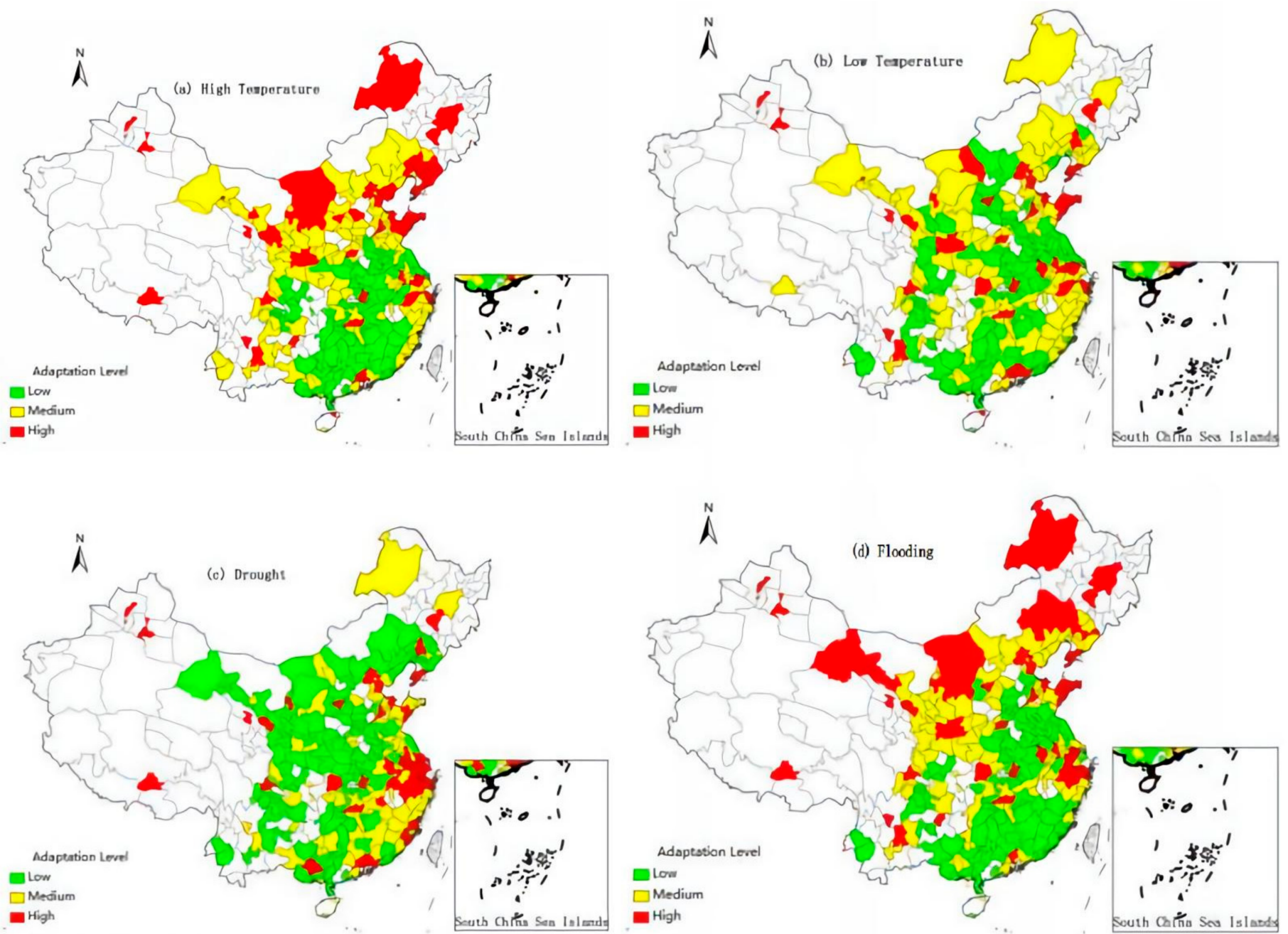

Figure 5. Spatial pattern of adaptation from a cities perspective. 
Table 2. List of cities with low adaptation under four types of climate events.

\begin{tabular}{ccc}
\hline Provinces & Cities & $\begin{array}{c}\text { Total Population } \\
\text { (Million) }\end{array}$ \\
\hline Jiangsu & Yancheng & 7.2422 \\
Shandong & Heze & 8.7360 \\
Jiangxi & Pingxiang, Ji'an & 6.8669 \\
Hunan & Hengyang, Shaoyang, Yongzhou, Loudi & 23.9780 \\
Hubei & Ezhou, Xiaogan, Jingzhou, Huanggang, Xianning, Suizhou & 22.7202 \\
Anhui & Huainan, Huaibei, Anqing, Chuzhou, Fuyang, Suzhou, Bozhou & 33.3530 \\
Henan & Pingdingshan, Puyang, Luohe, Nanyang, Shangqiu, & 42.0900 \\
Guangdong & Xinyang, Zhumadian & 32.0568 \\
Sichuan & Shaoguan, Shantou, Zhanjiang, Meizhou, Shanwei, Chaozhou, Jieyang & 29.5659 \\
Guangxi & Zigong, Luzhou, Suining, Neijiang, Nanchong, Guang'an, Dazhou & 24.2920 \\
& Fangchenggang, Qinzhou, Guigang, Yulin, Hezhou, Hechi, & Laibin, Chongzuo \\
\hline
\end{tabular}

\subsection{Spatial Correlation Features}

By using GeoDA software, the values of Moran's I indexes of cities' adaptation to four types of climate events were calculated, as shown in Figure 6. It can be seen from the figure that the values were all greater than 0 : high temperature 0.503 , low temperature 0.219 , drought 0.351 , and flooding 0.425 , all of which were positively correlated in space. In order to enhance the robustness of the results, Moran's I values were tested using Monte Carlo simulation, and the $p$-values were all significant at the 0.01 level, indicating that the spatial agglomerations of adaptation were significant. That is to say, cities with a higher adaptation to climate change had a positive impact on the improvement of adaptation of neighboring cities and vice versa. Meanwhile, according to Moran's I values, there were differences in the agglomeration characteristics of cities' adaptation to the four types of climate events. For high temperature, the spatial positive correlation was the most significant and the degree of spatial agglomeration was the highest, followed by flooding, and the positive correlation of low temperature was the weakest. The cities' adaptation to climate change in China showed four spatial patterns of $\mathrm{H}-\mathrm{H}, \mathrm{L}-\mathrm{H}, \mathrm{L}-\mathrm{L}$, and $\mathrm{H}-\mathrm{L}$, and the distribution quadrants of these cities are also shown in Figure 6. In general, these cities are mainly distributed in the first and third quadrants under all four types of climate events, indicating that the agglomeration characteristics of adaptation were mainly $\mathrm{H}-\mathrm{H}$ and $\mathrm{L}-\mathrm{L}$ agglomerations, which further validated the conclusion that the global spatial correlations were positive. In addition, most of the cities in the Yangtze River Delta region were located in the first quadrant $(\mathrm{H}-\mathrm{H})$. The geographical location of this region is superior, the degree of economic integration is very high [53], and the development of cities in the region is fully coordinated and integrated. Therefore, the cities in the fourth quadrant $(\mathrm{H}-\mathrm{L})$ had strong adaptation to climate change, and the adaptation gap was small. Moreover, most of the cities in the fourth quadrant $(\mathrm{H}-\mathrm{L})$ were high-administrative-level cities, which indicated that these cities had stronger social, economic, and governance capabilities than the surrounding cities [47] and had more significant advantages in coping with climate events.

The above analysis showed that it is meaningful to explore the characteristics of adaptation differences and the underlying reasons from the spatial perspective, and it also paved the way for later analysis of the impact factors on cities' adaptation to climate change in China by using spatial econometric methods to construct models. 

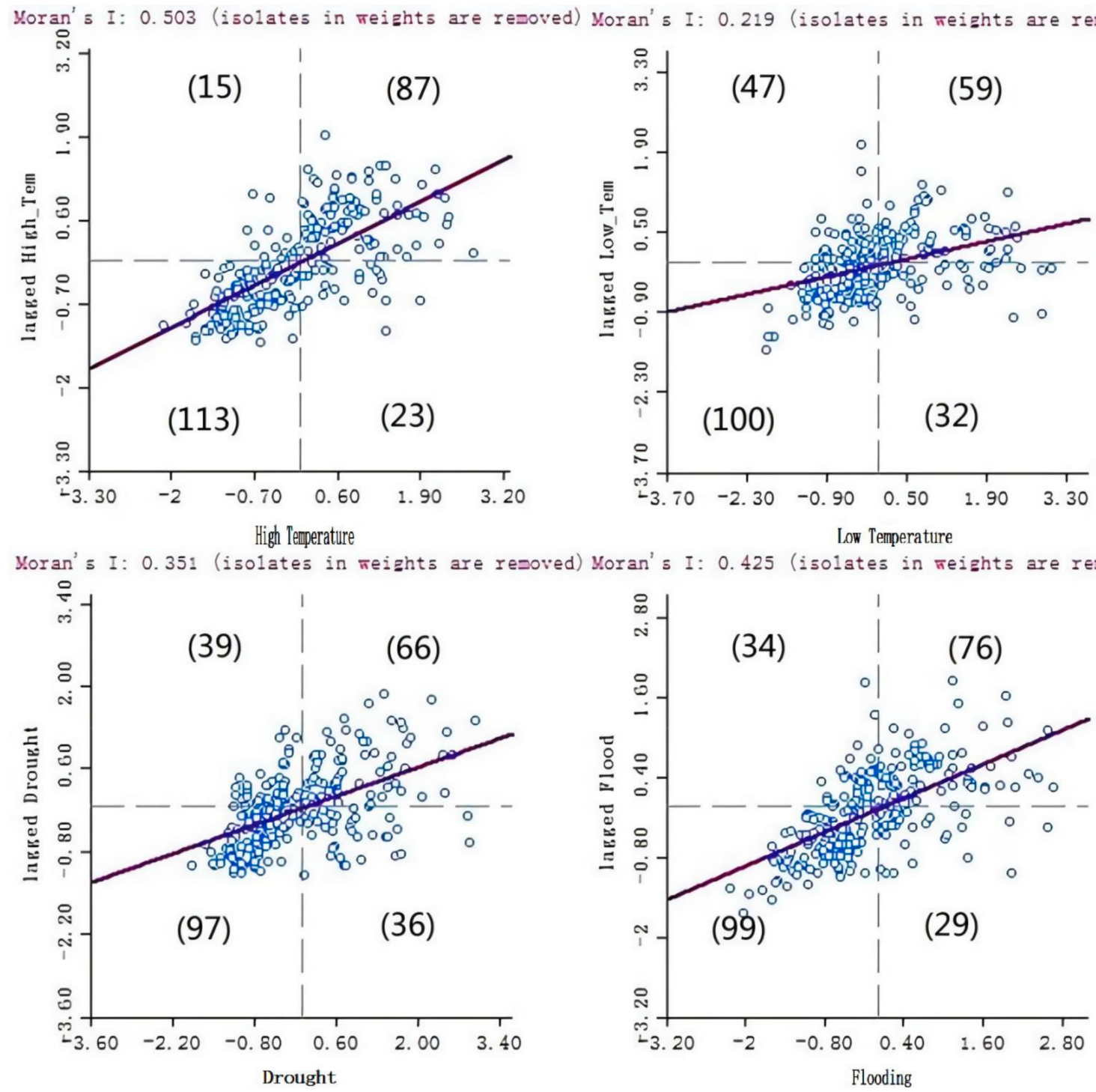

Figure 6. Spatial correlation features of adaptation. Note: 10 cities were removed due to the nonexistence of adjacent samples, but this did not affect the reliability of the conclusions.

\section{Analysis on How Urbanization Affecting Adaptation}

\subsection{Variables Selection}

Based on the interpretation and summary of the connotation of urbanization by the existing literature [54-57] and considering the availability and scientificity of data, this study selected four independent variables to explore the impact factors on spatial differentiation of cities' adaptation to climate change in China: population urbanization (PU), economic urbanization (EU), land urbanization (LU), and industrial urbanization (IU). These respectively represent four indicators: the proportion of urban residents, the per capita disposable income of urban residents, the ratio of urban built-up area to the total city area, and the proportion of secondary and tertiary industries.

One of the prerequisites for multiple regression is that there is no multicollinearity between independent variables. In the regression analysis, after standardizing the four indicators, the variance inflation factor (VIF) method was used to diagnose the existence of multicollinearity. The regression results in Table 3 show that the VIF values of all indicators were less than three, indicating that there was no multicollinearity or very weak covariance between independent variables [58], which met the basic requirements of regression analysis. 
Table 3. Multicollinearity test of influencing factors on adaptation.

\begin{tabular}{cccc}
\hline Impact Factors & Selected Variables & \multicolumn{2}{c}{ Collinearity Statistics } \\
\cline { 3 - 4 } & & Tolerance & VIF \\
\hline Population urbanization (PU) & The proportion of urban residents & 0.345 & 2.896 \\
Economic urbanization (EU) & Per capita disposable income of urban residents & 0.462 & 2.164 \\
Land urbanization (LU) & The ratio of urban built-up area to the total city area & 0.648 & 1.544 \\
Industrial urbanization (IU) & The proportion of secondary and tertiary industries & 0.436 & 2.292 \\
\hline
\end{tabular}

\subsection{Analysis of Regression Results}

With the adaptation scores of all cities under four types of climate events as dependent variables and four indicators as independent variables, the OLS stepwise regression analysis was conducted. The regression results showed that at the $1 \%$ significance level, only the proportion of urban residents was included in the high-temperature OLS model; the proportion of urban residents and per capita disposable income of urban residents were included in the low-temperature OLS model; the proportion of urban residents, per capita disposable income of urban residents, and the proportion of secondary and tertiary industries were included in the drought OLS model; and the proportion of urban residents, per capita disposable income of urban residents, and the ratio of urban built-up area to total city area were included in the flooding OLS model. All the above OLS models included independent variables that had positive coefficients, except for the ratio of urban built-up area to total city area, indicating that all three variables contributed positively to cities adaptation to climate events.

However, from the previous spatial autocorrelation analysis, it can be seen that the spatial distribution pattern of adaptation was not completely random but showed significant characteristics of spatial agglomeration and heterogeneity, which confirms Tobler's first law of geography: everything is related to everything else, but near things are more related to each other [59]. Moreover, it also shows that the results and inferences estimated by the classical linear regression model were likely to be less reliable because the OLS model can only estimate the parameters in the "global" or "average" level. Hence, this model failed to reflect the local changes in space, revealed the spatial dependence of cities' adaptation, and showed that modification by introducing spatial factors (spatial differences and dependencies) is extremely necessary and meaningful. Therefore, on the basis of the OLS model, the component (coordinates) reflecting heterogeneity were included and the GWR models were used for regression analysis. The results of the OLS and GWR models were compared in Table 4, and the regression parameters of the GWR model were statistically described in Table 5.

Table 4. Comparison of statistics between OLS and GWR models.

\begin{tabular}{cllccc}
\hline Climate Events & Model & \multicolumn{1}{c}{ AICc } & \multicolumn{1}{c}{$\boldsymbol{R}^{\mathbf{2}}$} & $\boldsymbol{R}_{\text {adj }}{ }^{\mathbf{2}}$ & RSS \\
\hline \multirow{2}{*}{ High temperature } & OLS & -724.861585 & 0.354301 & 0.349030 & 0.761955 \\
& GWR & -932.710281 & 0.784834 & 0.743669 & 0.253906 \\
Low temperature & OLS & -959.812847 & 0.549487 & 0.543948 & 0.293000 \\
& GWR & -1030.611852 & 0.751280 & 0.694895 & 0.161760 \\
Drought & OLS & -910.294683 & 0.597264 & 0.590635 & 0.037822 \\
& GWR & -949.188338 & 0.730269 & 0.679576 & 0.237600 \\
Flooding & OLS & -886.657301 & 0.375056 & 0.364769 & 0.390237 \\
& GWR & -1056.719260 & 0.798689 & 0.733256 & 0.125705 \\
\hline
\end{tabular}


Table 5. The estimation results of the sGWR models.

\begin{tabular}{|c|c|c|c|c|c|c|c|}
\hline Climate Event & Urbanization & Upper Quartile & Median & Lower Quartile & Maximum & Minimum & Mean \\
\hline $\begin{array}{c}\text { High } \\
\text { temperature }\end{array}$ & PU & 0.003969 & 0.003603 & 0.00285 & 0.006340 & 0.001620 & 0.003490 \\
\hline \multirow{2}{*}{$\begin{array}{c}\text { Low } \\
\text { temperature }\end{array}$} & PU & 0.002654 & 0.001833 & 0.001136 & 0.004500 & -0.000300 & 0.001883 \\
\hline & EU & 0.042054 & 0.029774 & 0.016489 & 0.077246 & -0.030578 & 0.027998 \\
\hline \multirow{3}{*}{ Drought } & PU & 0.002260 & 0.001134 & 0.000362 & 0.003704 & -0.001385 & 0.001303 \\
\hline & EU & 0.039992 & 0.029926 & 0.013831 & 0.061970 & -0.010707 & 0.026198 \\
\hline & $\mathrm{IU}$ & 0.002715 & 0.001678 & 0.000829 & 0.005290 & -0.001081 & 0.001824 \\
\hline \multirow{3}{*}{ Flooding } & PU & 0.002978 & 0.001999 & 0.000715 & 0.005129 & -0.001514 & 0.001923 \\
\hline & EU & 0.033977 & 0.022143 & 0.011767 & 0.067194 & -0.036343 & 0.022239 \\
\hline & LU & -0.067807 & -0.565335 & -0.291919 & 1.110860 & -1.957615 & -0.281499 \\
\hline
\end{tabular}

It can be seen from Table 4 that the adjusted goodness-of-fit indexes $\left(\mathrm{R}_{\mathrm{adj}}{ }^{2}\right)$ of the GWR models for the four types of climate events were $0.744,0.695,0.680$, and 0.733 for high temperature, low temperature, drought, and flooding, respectively, which were greater than the values of the corresponding OLS models. Meanwhile, the RSS values of the GWR models were far less than those of the OLS models, indicating that the fitting effects of the GWR models were better than the OLS models, with small errors and a better interpretation effect. In addition, the AICc values of the GWR models were smaller and the differences from the OLS models were much greater than 3, which further showed that the GWR models had better performance [60]. As mentioned above, the GWR models consider the local aspect; therefore, the measurement results are better than the OLS models, which only consider the mean parameters [46].

Table 5 shows the quintile statistics results. The mean values reflected the average level of contribution of the impact factors to cities' adaptation to climate change, and it can be seen that all factors, except for the land urbanization factor, contributed positively to adaptation in general, which was consistent with the analysis results of the OLS models. There were significant directional heterogeneities in the maximum and minimum values of the regression coefficients of some impact factors, which also indicated that the regression coefficients were non-stationary according to the geographical locations of cities, i.e., there were significant spatial differences in the degree and direction of the role of different impact factors on cities' adaptation to climate change.

The positive and negative distributions of the regression coefficients of the four types of urbanization are statistically presented in Figure 7. It can be seen that PU, EU, and IU had positive impacts on the adaptation to climate events in most cities, where PU played a positive role in enhancing adaptation to high temperature in all cities, while land urbanization has a negative impact, i.e., a hindering effect on adaptation to flooding in most cities.

However, simple statistical analysis cannot reflect the specific differences between cities. In order to more intuitively analyze the spatial variations of the impact factors on cities' adaptation to climate change in China, ArcGIS was used to draw spatial distribution maps of the regression coefficients of each variable in the GWR models. 


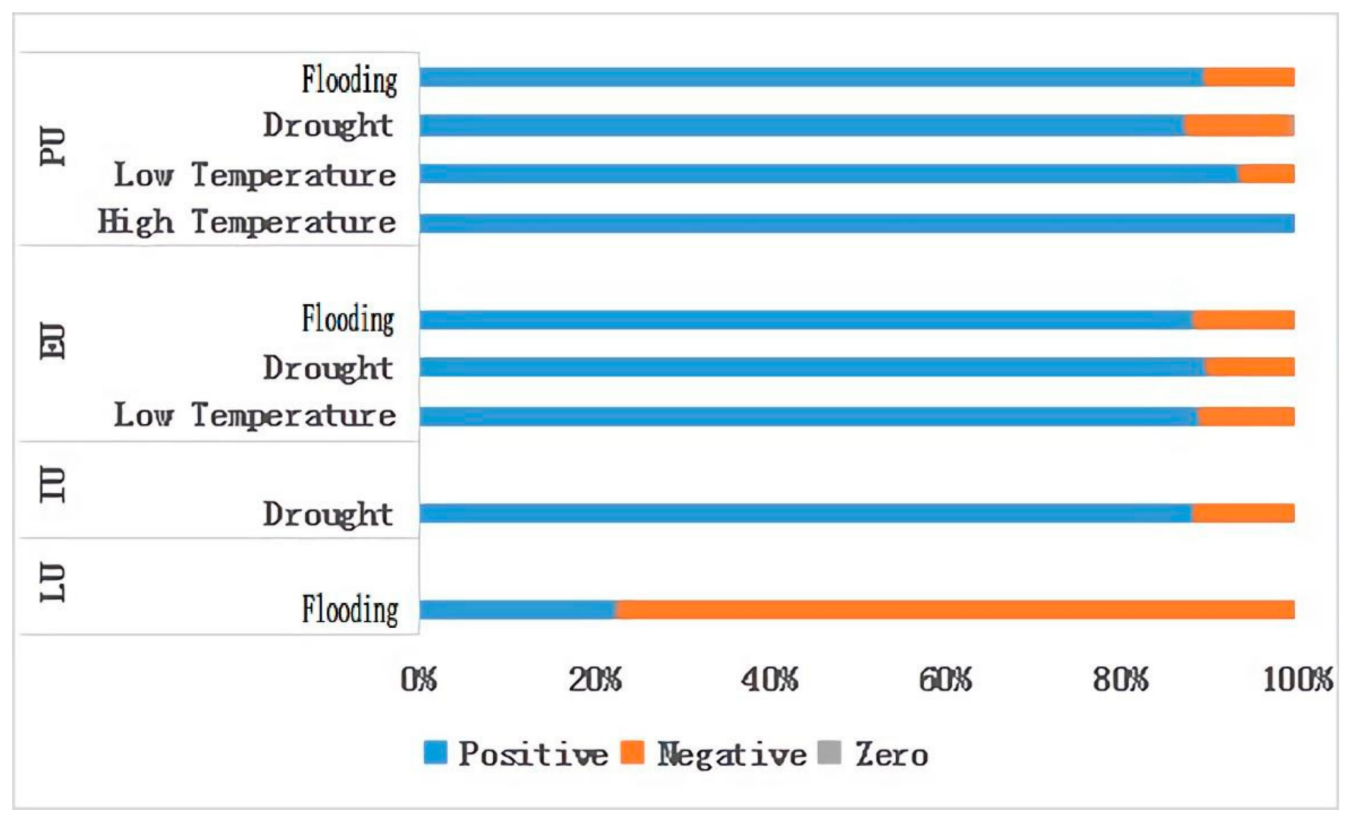

Figure 7. Positive and negative statistics of the regression coefficients.

Population urbanization: As shown in Figure 8, the regression coefficients of PU decreased from southwest to northeast. The Central Plains region, connecting the two directions, was always at a high value, while the economically developed Pearl River Delta region was always at a low-medium value. It is not difficult to see that Northeastern China took the lead in industrialization and had an early and high starting point in urbanization development [61], and as the vanguard of China's reform and opening up, the Pearl River Delta region has a high level of economic integration and complete infrastructure [62], both of which are highly attractive to the population. Therefore, their urbanization rates of the permanent resident population rank among the top in China. While Southwestern China and Central Plains are both underdeveloped areas, and the urbanization rates still lag behind the national average level, they are currently in the stage of rapid development. Population overurbanization is characterized by massive population inflow or natural population growth that outpaces the development of urban infrastructure, systems, and services, meaning city governance will become more difficult, thereby increasing vulnerability or decreasing readiness to climate change. The floating population in the Pearl River Delta is mainly educated at the junior high school level, and most of them are engaged in labor-intensive industries and business service industries rather than scientific and technological industries, which does not help to improve the adaptation level from the technical aspect. Meanwhile, a large number of urban villages pose challenges to land use, urban landscape, planning and management, and community security. Nowadays, the overall economy of Northeastern China is in recession, and the mismatch between the economic development level and urbanization level means climate change may bring greater risks and challenges [63]. Due to the existence of the marginal diminishing effect, PU has weak and even negative effects on the adaptation of the two regions, while it has positive effects on Southwestern China and the Central Plains. In addition, it is worth noting that PU has a limited role in enhancing cities' adaptation to high temperature in Northwestern China, while it has a significant positive contribution to their adaptation to low temperature and flooding, which also indicates that the PU sensitivity of cities' adaptation varied significantly depending on climate events. 

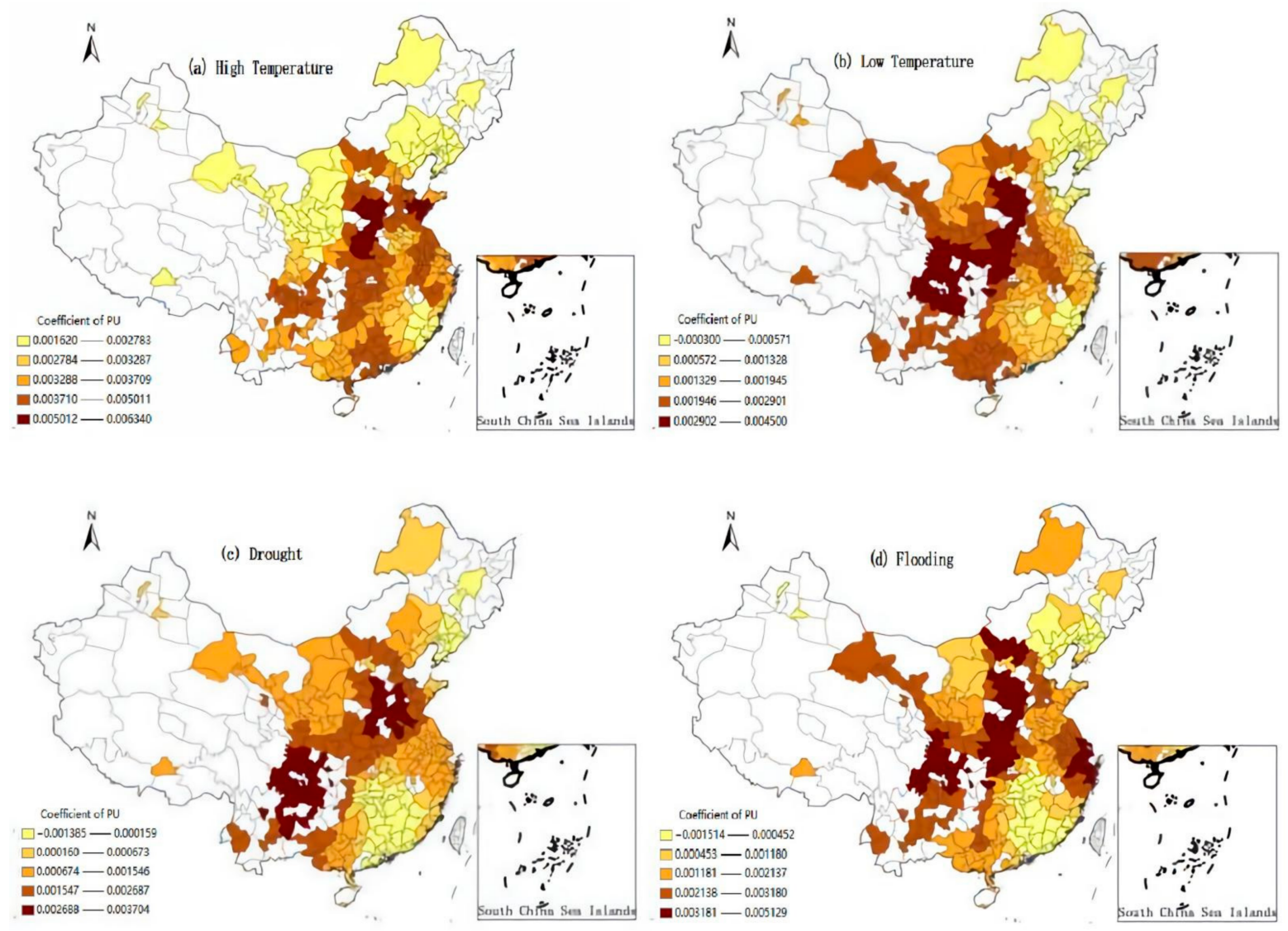

Figure 8. Regression coefficients of population urbanization.

Economic urbanization: We can see from Figure 9 that the regression coefficients of PU of adaptation to low temperature, drought, and flooding showed highly similar distribution trends: the middle-high-value areas were mainly located to the east of the $\mathrm{Hu}$ Line, while the low-value areas were distributed to the west of the line, with most cities having negative coefficients. West of the Hu Line is the less developed area in China, where the economic development is relatively backward. Therefore, the disposable income of urban residents there is not high, and the adaptation to low temperature and drought are also at a low level, which indicates that the development of EU in this area has limited pulling power and a weak impact on the level of adaptation to low temperature and drought. The cities with high values are located in the belt-shaped region consisting of Southern China, Central China, Northern China, and Northeastern China, and the development of EU had a significant positive impact on the improvement of their adaptation level. Since EU is expressed by per capita disposable income of urban residents, it is possible that with more income, residents can buy more facilities and services to protect against climate events, thereby reducing personal and property damage and improving their adaptation ability. 

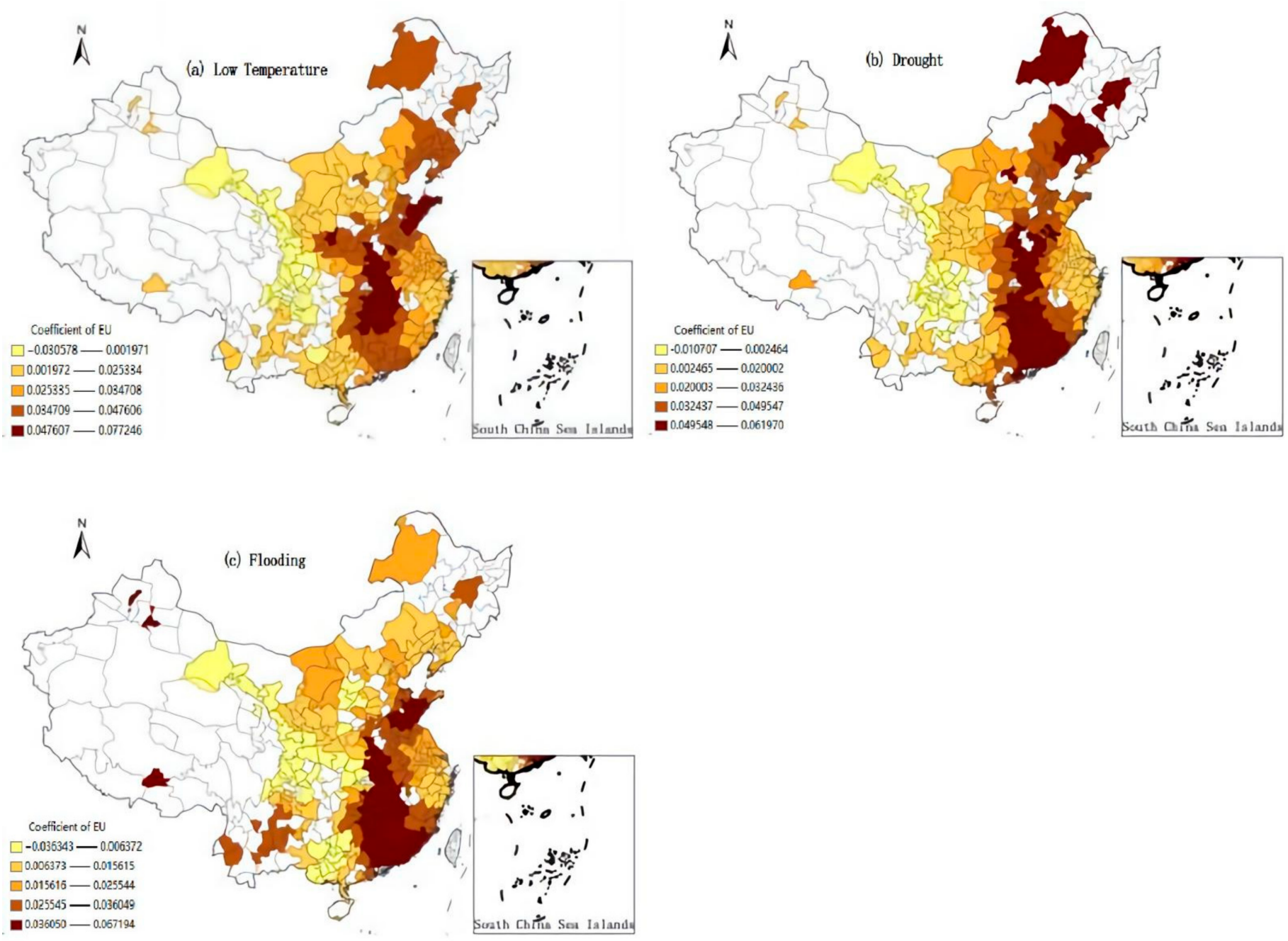

Figure 9. Regression coefficients of economic urbanization.

Land urbanization: As shown in Figure 10, the coefficients of LU varied greatly between cities, with the range reaching 3.07, indicating that the process of LU varied greatly between these cities. LU played an extremely critical role in cities' adaptation to flooding. High-value cities were clustered in Northwestern China, Southern China, Central China, and Northeastern China; most cities with low coefficients were located in Eastern China, especially in coastal provinces, and the coefficients were even negative. The eastern cities have superior geographical locations, rapid economic development, and early urban planning and infrastructure construction, which has lasted for a long time. However, in recent years, the continuous expansion of urban boundaries has accelerated the concentrated outbreak of urban problems, such as traffic congestion and housing shortages. The resources and environment of these cities are under great pressure, and the disaster resistance abilities and disaster management level are significantly inadequate. In this context, it is not surprising that LU had a negative impact on these cities' adaptation to flooding. 


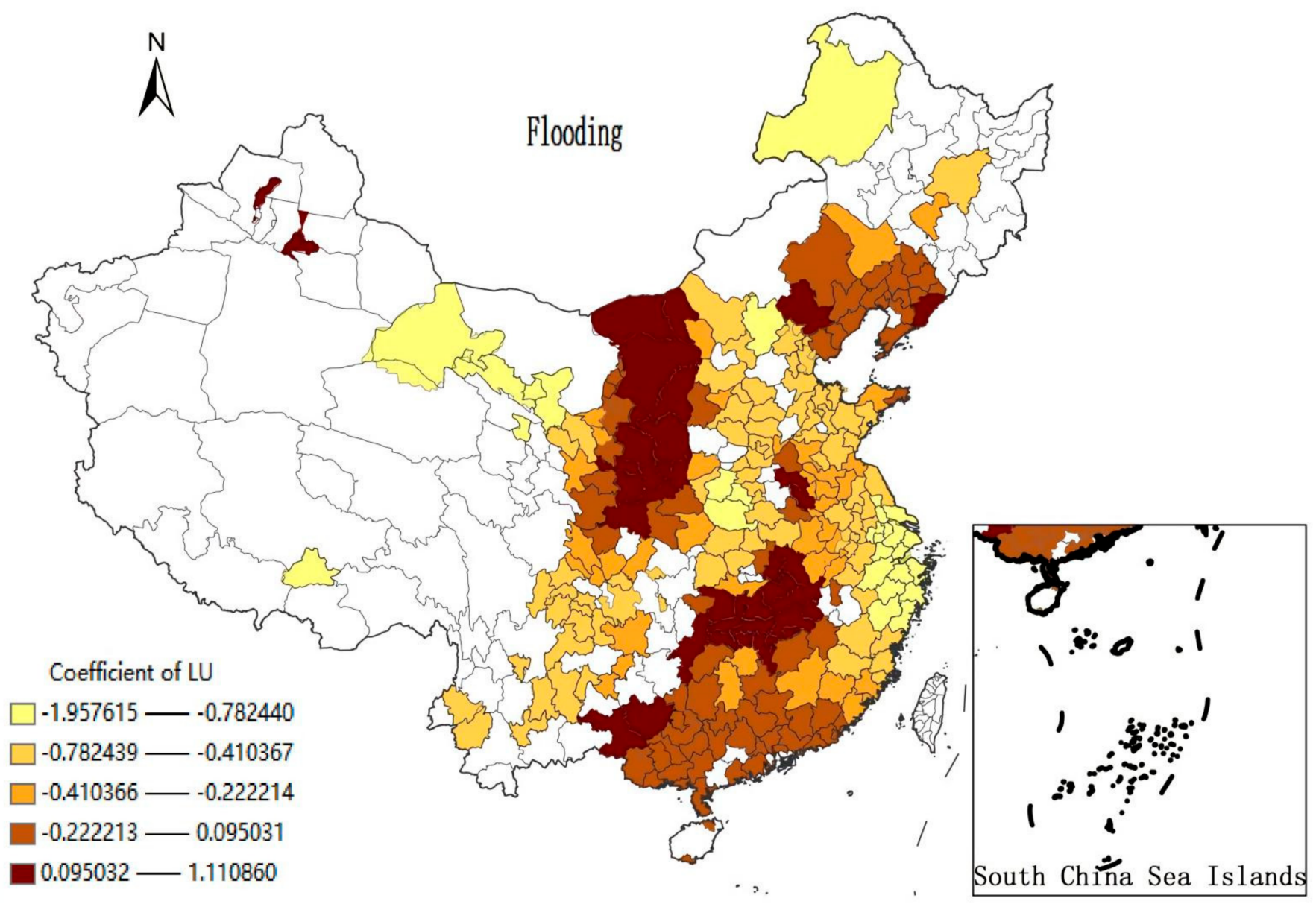

Figure 10. Regression coefficients of land urbanization.

Industrial urbanization: Figure 11 shows that the high-value areas presented a beltshaped distribution, mainly located in Jiangsu, Zhejiang, Shanghai, Anhui, and Jiangxi in Eastern China and Hunan and Hubei in Central China, while the low-value areas were mainly located in Fujian Province and the Shanxi-Hebei-Henan region. In addition, some cities in Xinjiang, Gansu, and Shandong were also at a high-value level. The high coefficient cities had a high level of IU relative to the rest of the country, with a diversified industrial pattern or a large proportion of the output value of the dominant industry and, thus, IU had a significant positive driving impact on their adaptation to drought. For example, the city of Karamay in Xinjiang is an industrial city with petroleum and petrochemical industries as the main industry. In 2019, the secondary industry accounted for $70 \%$, while agriculture only accounted for $1.5 \%$. In comparison, low-value areas are either weak in terms of their industrial economy or singular in their industrial structure. For example, Henan is a typical agricultural province, and the level of secondary and tertiary industries in its cities is relatively backward. From the assessment results, most of these cities have low values, and the IU process cannot play a significant role in promoting adaptation to drought. Moreover, Hebei is a large industrial province, not a powerful one, and mainly contains iron and steel industries with high pollution, high energy consumption, and low added value. Thus, the IU of Hebei did not play a significant positive role in economic development and environmental health. The low-quality IU did not improve the adaptation to drought but became an obstacle factor. To a certain extent, this also indicated that it is very urgent to enhance the industrial output values of cities with low IU coefficients and optimize and adjust their singular or unreasonable industrial structure. 


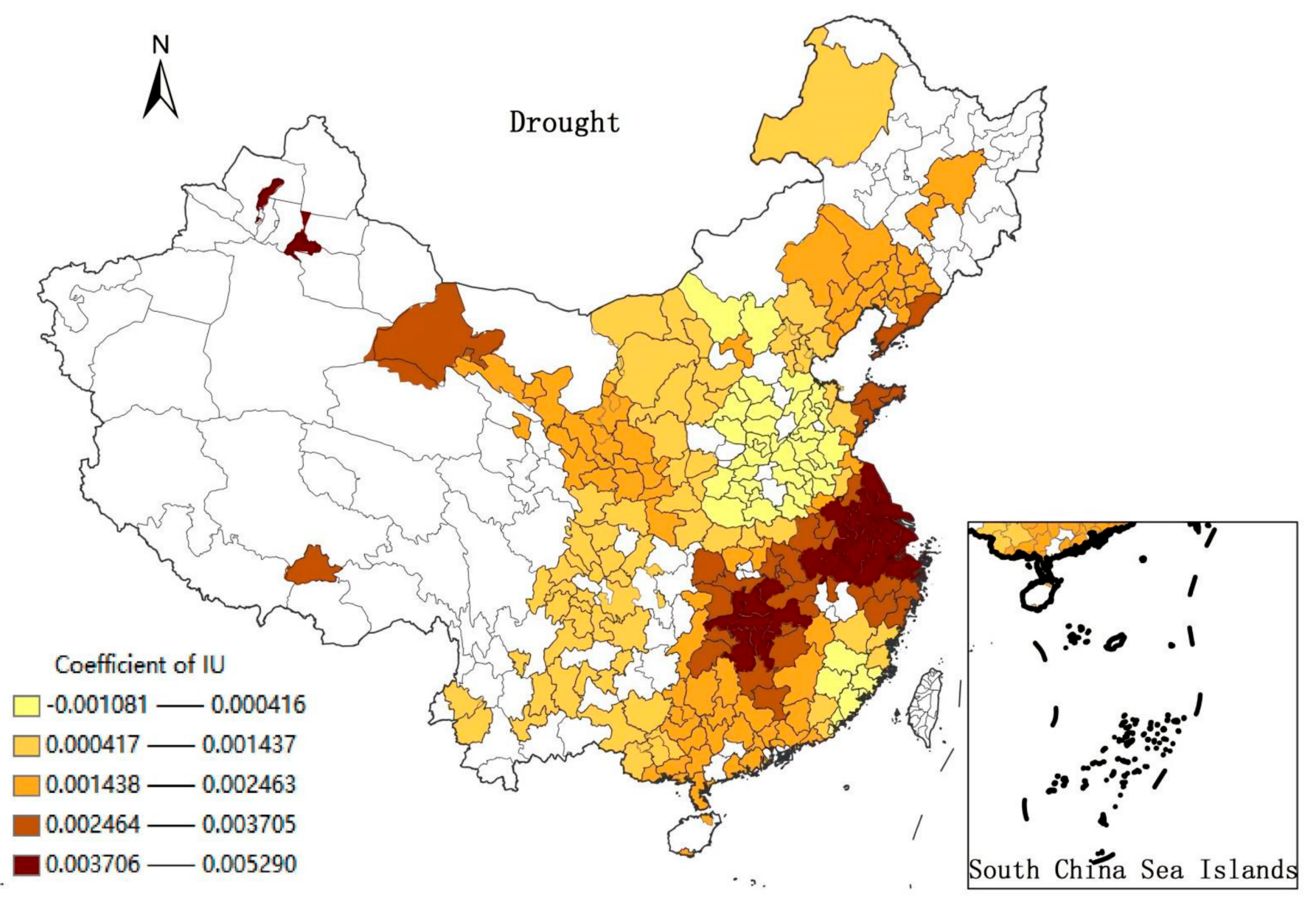

Figure 11. Regression coefficients of industrial urbanization.

\section{Conclusions and Implications}

\subsection{Conclusions}

Based on the data of 248 cities in China, this study constructed assessment indicator systems of cities' adaptation to climate change under four types of climate events: high temperature, low temperature, flooding, and drought. In addition, the coefficient of variation method and ESDA were used to analyze the spatial differences characteristics of cities' adaptation, and a GWR model was used to explore how urbanization affected adaptation. The conclusions were as follows.

The spatial pattern analysis showed that the adaptation to climate change varied substantially across China [13]. Compared with Southern China, Northern China had a wider advantage in adapting to climate change and climate events and the key to improving balanced adaptation to climate change in all regions of China lies in narrowing the gap in adaptation to high temperature. The cities' adaptation to high temperature and flooding were characteristic of high in the north and low in the south; cities with high adaptation to low temperature mainly belonged to high-administrative-level; cities' adaptation to drought showed a significant trend of decreasing from southeast to northwest. High-administrative-level cities had stronger adaptation, lower vulnerability, and higher readiness than ordinary prefecture-level cities, but the agglomeration characteristics of cities' adaptation were mainly $\mathrm{H}-\mathrm{H}$ and L-L agglomerations. These two findings showed the importance of economic development level, social security system, governance institution, and social-economic integration from different aspects. The coordinated and integrated development between cities was conducive to narrowing the adaptation gap, which is consistent with earlier studies $[64,65]$. 
When analyzing the factors, the fitting effects of the GWR models were far better than those of the OLS models. Population urbanization affected cities' adaptation to four types of climate events; economic urbanization on low temperature, drought, and flooding; industrial urbanization on drought; and land urbanization on flooding. Population, economic, and industrial urbanization had positive impacts on the adaptation of most cities. Population urbanization could improve the adaptation of all cities to high temperature, while land urbanization hindered the adaptation of most cities to flooding. Under the influence of social and economic development, the urbanization regression coefficients of different cities had significant spatial differences.

\subsection{Implications}

The above findings suggested meaningful theoretical and policy implications. First, there were adaptation gaps between cities at different levels and between regions. This was not only due to natural conditions but also disparities in socioeconomic and technological levels [13], as high-level cities were more dominant in all aspects. It is suggested that to bring China's adaptation to climate change to a higher level, when formulating adaptation strategies, the Chinese government should fully consider these differences and provide financial and technical support to low-adaptation cities or regions; moreover, paired assistance between cities is also extremely necessary. In addition, the governing authorities should attach importance to the development of economy, science, and technology; increase the investment of adaptive funds; provide more basic protective infrastructure and services for the public; help the relevant organizations to actively popularize adaptive knowledge to the public; and help the public to gain more income to enhance economic readiness [35].

Second, the impacts of urbanization on adaptation showed that massive population agglomeration to urban areas such as Northeastern China and the Pearl River Delta, and the blind expansion of city construction land, such as eastern coastal areas, were both not conducive to cities' climate governance and will undermine cities' sustainable development. Therefore, when carrying out urban planning, managers should clarify the nature, scale, and development direction of cities, make rational use of urban land, coordinate urban spatial layout and various constructions, and fully consider cities' resource-carrying capacity. At the same time, inappropriate urbanization will contribute to social unrest, such as violence in urban villages under the background of population overurbanization, which is not only closely related to poverty [66] but also adversely affects the adaptation of communities and individuals. Therefore, the authorities and relevant social organizations need to pay attention to solving social contradictions and building a harmonious society.

Third, most of the cities are currently in the middle and low adaptation levels; therefore, the following suggestions are put forward: cities should regularly carry out climate change risk monitoring and assessment work with dynamic follow up, fully understand cities' climate change risks and vulnerabilities, identify priority adaptation measures, and improve cities' adaptation effectiveness. Furthermore, the central and provincial governments need to formulate adaptive policies tailored to local conditions for different types of cities, especially by enhancing the ability of economic and social development to enhance cities' adaptation to climate change to achieve synergy between addressing climate change and sustainable development. The above suggestions may take China's adaptation to climate change to a higher level.

\subsection{Limitations}

Due to the limitation of time and data acquisition, a small part of the data for indicators were derived from the Internet or estimation, which may make the results not robust enough. Furthermore, the cross-sectional data cannot reflect the relative change in cities' adaptation to climate change from the time dimension. Finally, urbanization is a dynamic and long process, and cross-sectional urbanization variables cannot well reflect its dynamic impact on cities' adaptation to climate change. More accurate, comprehensive, and in-depth comparative studies are still needed. 
Author Contributions: Conceptualization, J.W.; Methodology, J.W. and J.X.; Software, X.P. and C.L.; Data Curation, J.Z., C.L. and Y.T.; Writing-Original Draft Preparation, X.P.; Writing-Review and Editing, J.W. and J.X. All authors read and agreed to the published version of the manuscript.

Funding: This research was supported by the National Natural Science Foundation of China (41871219 and 41971266).

Institutional Review Board Statement: Not applicable.

Informed Consent Statement: Not applicable.

Data Availability Statement: The data used in this study are available from the authors on reasonable request.

Acknowledgments: We appreciate the advice of the reviewers very much.

Conflicts of Interest: The authors declare no conflict of interest.

\section{Appendix A}

Table A1. Details of data sources.

\begin{tabular}{|c|c|c|c|}
\hline Indicators & Abbreviations & Reasons for Selection & Source \\
\hline Population density & PD & $\begin{array}{l}\text { The greater the number of people exposed to the } \\
\text { disaster-causing factors per unit area, the greater } \\
\text { the risk of life and health damage }\end{array}$ & \multirow{12}{*}{ China City Statistical Yearbook } \\
\hline $\begin{array}{l}\text { GDP per square kilometer } \\
\text { (economic density) }\end{array}$ & GPSK & $\begin{array}{l}\text { The higher the value of disaster-bearing body per } \\
\text { unit area is, the greater the economic loss will be }\end{array}$ & \\
\hline $\begin{array}{l}\text { Percentage of employees } \\
\text { working outdoors }\end{array}$ & PEWO & $\begin{array}{l}\text { People who work outdoors are vulnerable to high } \\
\text { and low temperatures, leading to health risks }\end{array}$ & \\
\hline $\begin{array}{l}\text { Proportion of employees in } \\
\text { primary industry }\end{array}$ & PEPI & $\begin{array}{l}\text { It reflects the sensitivity of drought susceptible } \\
\text { industries to drought at the level of employment } \\
\text { structure }\end{array}$ & \\
\hline $\begin{array}{l}\text { Proportion of primary } \\
\text { industry to GDP }\end{array}$ & PPIG & $\begin{array}{l}\text { It reflects the sensitivity of drought susceptible } \\
\text { industries to drought at the level of the economy }\end{array}$ & \\
\hline $\begin{array}{l}\text { Number of hospital beds } \\
\text { per capita }\end{array}$ & NHBPC & $\begin{array}{l}\text { Medical resources reflect the level of health } \\
\text { protection: the more beds per capita, the more } \\
\text { favorable is the post-disaster relief }\end{array}$ & \\
\hline Number of doctors per capita & NDPC & $\begin{array}{l}\text { Medical resources reflect the level of health } \\
\text { protection: the more doctors per capita, the more } \\
\text { favorable is the post-disaster relief }\end{array}$ & \\
\hline $\begin{array}{l}\text { Greening coverage of } \\
\text { built-up areas }\end{array}$ & GCBA & $\begin{array}{l}\text { Green space provides a cooling function, which } \\
\text { can reduce the impact of extreme heat and } \\
\text { biophysical hazards }\end{array}$ & \\
\hline Mobile phone ownership rate & MPOR & $\begin{array}{l}\text { Reflect the ability of early warning measures, } \\
\text { information exchange, etc. }\end{array}$ & \\
\hline Water resources per capita & WRPC & $\begin{array}{l}\text { Reflects the resource endowment to withstand } \\
\text { drought, as well as the ability to obtain drinking } \\
\text { water after floods }\end{array}$ & \\
\hline $\begin{array}{l}\text { Number of buses per } \\
10,000 \text { people }\end{array}$ & NBP & $\begin{array}{l}\text { Vehicles provide a more reliable evacuation option } \\
\text { in the event of a flood, while also making it easier } \\
\text { for cities to recover from weather disasters }\end{array}$ & \\
\hline GDP per capita & GPC & $\begin{array}{l}\text { A low value may lead to insufficient investment in } \\
\text { the construction of climate adaptation } \\
\text { infrastructure and affect the implementation of } \\
\text { post-disaster recovery }\end{array}$ & \\
\hline $\begin{array}{l}\text { Percentage of population } \\
\text { aged } 65 \text { and over }\end{array}$ & PPA65O & $\begin{array}{l}\text { The elderly have poor physical resistance ability, } \\
\text { weak self-protection, and disaster response ability }\end{array}$ & \multirow{2}{*}{$\begin{array}{l}\text { City-level Database of } \\
\text { Sixth Census }\end{array}$} \\
\hline $\begin{array}{l}\text { Percentage of population } \\
\text { aged } 0-4\end{array}$ & PPA0-4 & $\begin{array}{l}\text { Children have poor physical resistance ability, } \\
\text { weak self-protection, and disaster response ability }\end{array}$ & \\
\hline
\end{tabular}


Table A1. Cont.

\begin{tabular}{|c|c|c|c|}
\hline Indicators & Abbreviations & Reasons for Selection & Source \\
\hline $\begin{array}{l}\text { Percentage of population with } \\
\text { high school education } \\
\text { and above }\end{array}$ & PPHSEA & $\begin{array}{l}\text { Education helps raise a city's awareness of how to } \\
\text { respond to climate events }\end{array}$ & \\
\hline $\begin{array}{l}\text { Domestic water consumption } \\
\text { per capita }\end{array}$ & DWCPC & $\begin{array}{l}\text { It reflects the sensitivity of water demand after } \\
\text { climate change and water shortage }\end{array}$ & \multirow{4}{*}{$\begin{array}{l}\text { City-level Database of China Real } \\
\text { Estate Information }\end{array}$} \\
\hline $\begin{array}{l}\text { Density of drainage pipes in } \\
\text { built-up areas }\end{array}$ & DDPBA & $\begin{array}{l}\text { It reflects the drainage capacity in the case of } \\
\text { a'flood }\end{array}$ & \\
\hline Patents granted per capita & PGPC & $\begin{array}{l}\text { It reflects innovation ability; the higher the value, } \\
\text { the better the ability to find countermeasures } \\
\text { against the incident }\end{array}$ & \\
\hline $\begin{array}{l}\text { Loan-to-deposit ratio of } \\
\text { financial institutions }\end{array}$ & LRFI & $\begin{array}{l}\text { An indicator of economic development. If the } \\
\text { value is too low, it may indicate that the city is } \\
\text { unable to carry out the construction or investment } \\
\text { of adaptive projects }\end{array}$ & \\
\hline High-temperature days & HTD & $\begin{array}{l}\text { The number of days with daily maximum } \\
\text { temperature } \geq 35^{\circ} \mathrm{C} \text {; this is directly proportional } \\
\text { to the high-temperature risk }\end{array}$ & \multirow{6}{*}{$\begin{array}{l}\text { China Meteorological Data } \\
\text { Service Centre }\end{array}$} \\
\hline $\begin{array}{l}\text { Average value of highest } \\
\text { temperature in } \\
\text { high-temperature days }\end{array}$ & AVHTHTD & It is proportional to the risk of high temperature & \\
\hline Low-temperature days & LTD & $\begin{array}{l}\text { The number of days with daily minimum } \\
\text { temperature } \leq 0{ }^{\circ} \mathrm{C} \text {; this is directly proportional to } \\
\text { the low-temperature risk }\end{array}$ & \\
\hline $\begin{array}{l}\text { Average value of lowest } \\
\text { temperature in } \\
\text { low-temperature days }\end{array}$ & AVLTLTD & It is proportional to the risk of low temperature & \\
\hline Average annual precipitation & AAP & $\begin{array}{l}\text { The larger the value is, the greater the flood risk is } \\
\text { and the smaller the drought risk is }\end{array}$ & \\
\hline Average annual temperature & AAT & $\begin{array}{l}\text { The larger the value is, the more the city is } \\
\text { disturbed by drought }\end{array}$ & \\
\hline Housing price to income ratio & HPIR & $\begin{array}{l}\text { Housing cost burden is a high risk factor for } \\
\text { homelessness, and homeless or marginalized } \\
\text { populations are the most vulnerable to } \\
\text { adverse weather }\end{array}$ & $\begin{array}{l}\text { https:/ / www.creprice.cn/ } \\
\text { (accessed on 17 January 2022), } \\
\text { China Meteorological Data } \\
\text { Service Centre }\end{array}$ \\
\hline $\begin{array}{l}\text { Percentage of impervious } \\
\text { surface area }\end{array}$ & PISA & $\begin{array}{l}\text { The higher the value, the greater the amount of } \\
\text { surface runoff, exacerbating flooding }\end{array}$ & Calculated by the research group \\
\hline Heating situation & HS & $\begin{array}{l}\text { Whether a city has heating or not indicates how } \\
\text { well it can cope with cold-weather events }\end{array}$ & $\begin{array}{l}\text { Article of "map can talk" on } \\
\text { WeChat-Where is China's } \\
\text { heating demarcation line? }\end{array}$ \\
\hline $\begin{array}{l}\text { Whether it is a } \\
\text { water-saving city }\end{array}$ & WAWC & $\begin{array}{l}\text { It reflects the water management ability, and } \\
\text { water-saving cities can rationally allocate, develop, } \\
\text { and utilize water resources to form a scientific } \\
\text { water use system and effectively deal with drought }\end{array}$ & $\begin{array}{l}\text { Baidu Encyclopedia-National } \\
\text { water-saving cities }\end{array}$ \\
\hline $\begin{array}{l}\text { Government debt balance } \\
\text { per capita }\end{array}$ & GDBPC & $\begin{array}{l}\text { The higher the value is, the less investment is } \\
\text { likely to be put into the infrastructure construction } \\
\text { of adaptation to climate events, and the } \\
\text { implementation of post-disaster recovery will be } \\
\text { affected at the same time }\end{array}$ & $\begin{array}{l}\text { Everbright Securities Research } \\
\text { Report-Special Report on } \\
\text { Regional Finance }\end{array}$ \\
\hline $\begin{array}{l}\text { Number of corruption and } \\
\text { bribery cases per } \\
10,000 \text { people }\end{array}$ & $\mathrm{NCBC}$ & $\begin{array}{l}\text { It reflects the level of free from corruption, the } \\
\text { transparency and management capacity of local } \\
\text { governments, and the level of effective use of } \\
\text { climate funds }\end{array}$ & $\begin{array}{l}\text { Harvard University-China } \\
\text { Corruption Survey Dataset }\end{array}$ \\
\hline
\end{tabular}


(a) High Temperature

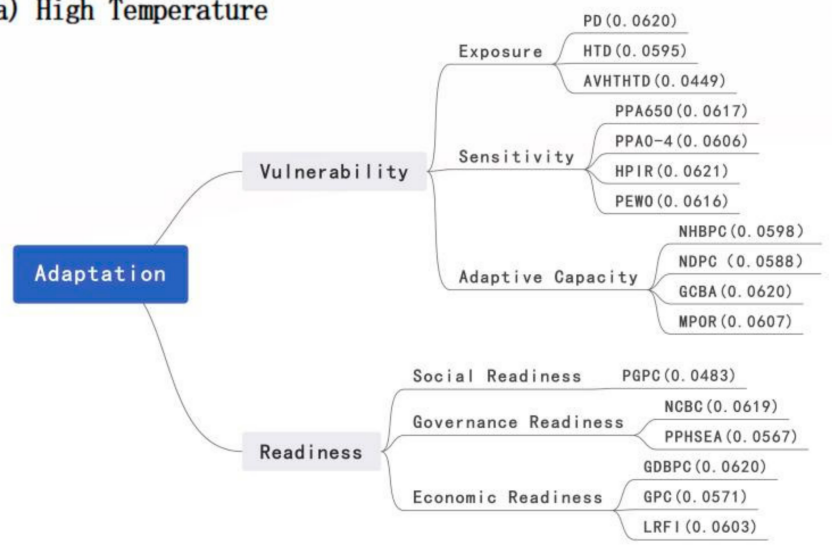

(b) Low Temperature

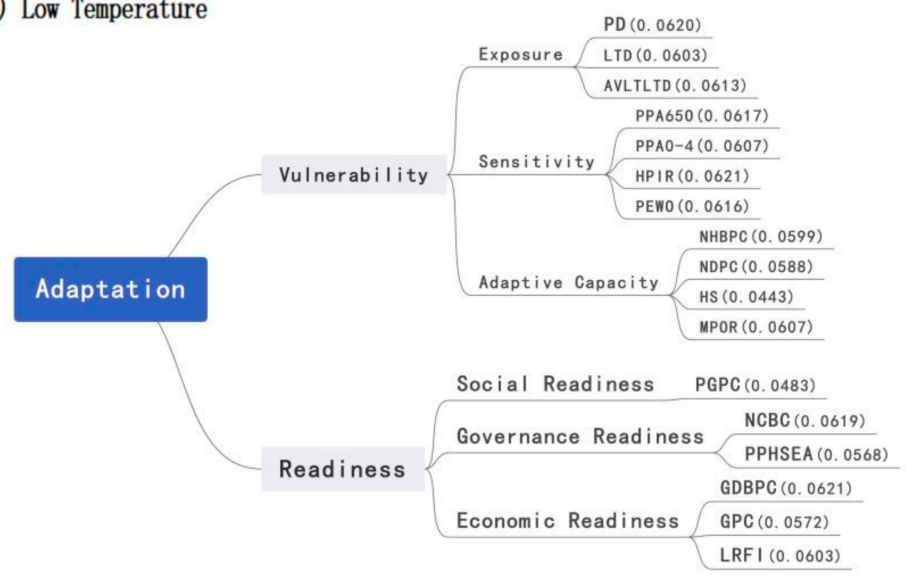

(c) Drought

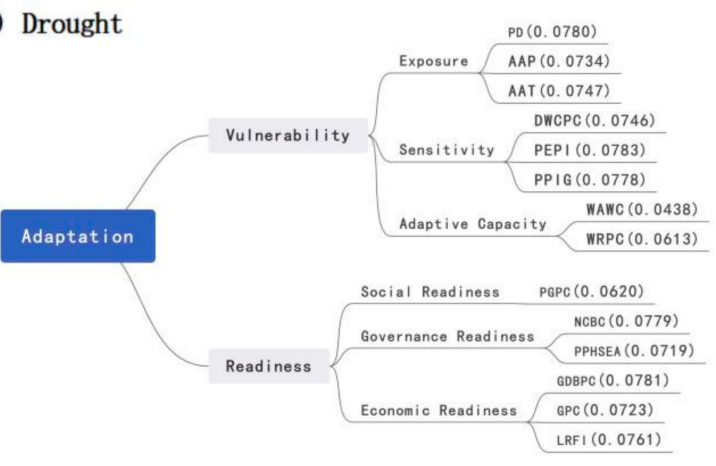

(d) Flooding

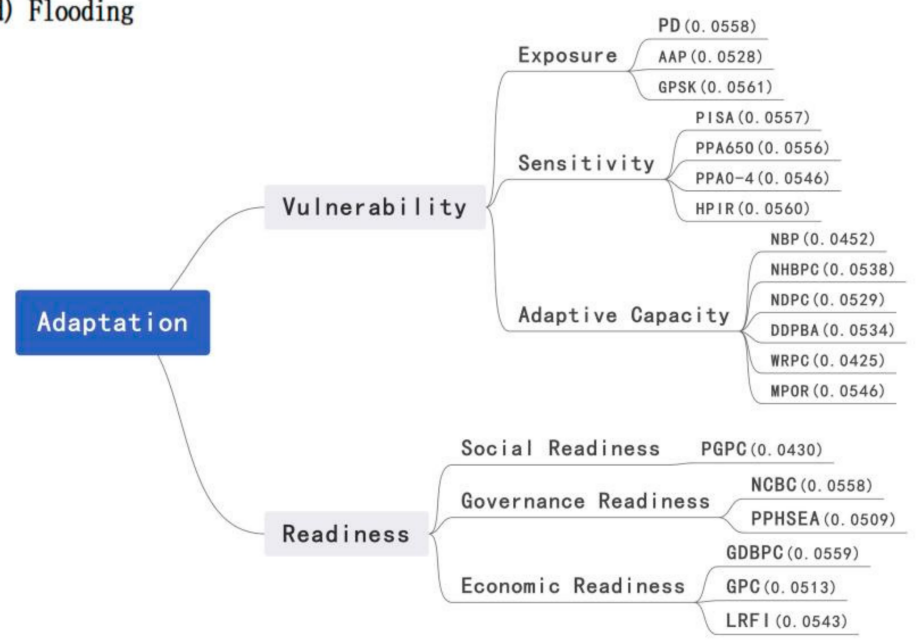

Figure A1. Assessment system of cities' adaptation to climate change. (Note: The values in parentheses are the weights of each indicator calculated based on the entropy weight method).

\section{References}

1. IPCC. Climate Change 2021: The Physical Science Basis [M/OL]. 2021. Available online: https://www.ipcc.ch/report/ar6/wg1 /downloads/report/IPCC_AR6_WGI_Full_Report.pdf (accessed on 17 January 2022).

2. Akbari, H.; Cartalis, C.; Kolokotsa, D.; Musico, A.; Pisello, A.; Rossi, F.; Santamouris, M.; Synnefa, A.; Wong, N.H.; Zinzi, M.; et al. Local climate change and urban heat island mitigation techniques-The state of the art. Statyba 2016, 22, 1-16. [CrossRef]

3. Chen, Y. Some opinions on developing researches on regional adaptation to global change. Adv. Earth Sci. 2004, 19, 495-499.

4. Smith, J.B.; Ragland, S.E.; Pitts, G.J. A process for evaluating anticipatory adaptation measures for climate change. Water Air Soil Pollut. 1996, 92, 229-238. [CrossRef]

5. Pielke, R.A. Rethinking the role of adaptation in climate policy. Glob. Environ. Chang. 1998, 8, 159-170. [CrossRef]

6. Doria, M.; Boyd, E.; Tompkins, E.L.; Adger, W.N. Using expert elicitation to define successful adaptation to climate change. Environ. Sci. Policy 2009, 12, 810-819. [CrossRef]

7. O'Brien, K. Global environmental change II From adaptation to deliberate transformation. Prog. Hum. Geogr. 2012, 36, 667-676. [CrossRef]

8. UNDP. Monitoring and Evaluation Framework for Adaptation to Climate Change, Draft for Comments; United Nations Development Programme: New York, NY, USA, 2007; pp. 25-46.

9. $\quad$ Brink, E.; Aalders, T.; Dóra, A.; Robert, F.; Yuki, H.; Alexander, H.; Karin, I.; Aude, M.-D.; Moritz, M.; Mergut, N.; et al. Cascades of green: A review of ecosystem-based adaptation in urban areas. Glob. Environ. Chang. 2016, 36 (Suppl. 1), 111-123. [CrossRef]

10. Kuang, Y.; Hao, L.I.; Xia, J.; Yang, Z.C. Impacts of climate change on transboundary water resources and adaptation management framework. Clim. Chang. Res. 2018, 14, 67-76.

11. Aguiar, F.C.; Bentz, J.; Silva, J.; Fonseca, A.; Swart, R.; Santos, F.D.; Gil, P.-L. Adaptation to climate change at local level in Europe: An overview. Environ. Sci. Policy 2018, 86, 38-63. [CrossRef]

12. Araya-Mu, O.D.; Metzger, M.J.; Stuart, N.; Wilson, A.M.W.; Alvarez, L. Assessing urban adaptive capacity to climate change. J. Environ. Manag. 2016, 183, 314-324. [CrossRef] 
13. Zhao, C.; Chen, J.; Su, G.; Yuan, H. Assessment of the climate change adaptation capacity of urban agglomerations in China. Mitig. Adapt. Strateg. Glob. Chang. 2020, 25, 221-236. [CrossRef]

14. Bachner, G.; Bednar-Friedl, B.; Knittel, N. How does climate change adaptation affect public budgets? Development of an assessment framework and a demonstration for Austria. Mitig. Adapt. Strateg. Glob. Chang. 2019, 24, 115-133. [CrossRef]

15. Cupać, R.; Trbić, G.; Zahirović, E. Cost-benefit analysis of climate change adaptation measures in Bosnia and Herzegovina. Euro-Mediterr. J. Environ. Integr. 2020, 5, 26. [CrossRef]

16. Huang-Lachmann, J.T.; Hannemann, M.; Guenther, E. Identifying Links between Economic Opportunities and Climate Change Adaptation: Empirical Evidence of 63 Cities. Ecol. Econ. 2018, 145, 231-243. [CrossRef]

17. Liddle, B. Urban density and climate change: A STIRPAT analysis using city-level data. J. Transp. Geogr. 2013, 28, 22-29. [CrossRef]

18. Wang, Y.; Li, L.; Kubota, J.; Han, R.; Zhu, X.; Lu, G. Does urbanization lead to more carbon emission? Evidence from a panel of BRICS countries. Appl. Energy 2016, 168, 375-380. [CrossRef]

19. Miao, L. Examining the impact factors of urban residential energy consumption and $\mathrm{CO}_{2}$ emissions in China-Evidence from city-level data. Ecol. Indic. Integr. Monit. Assess. Manag. 2017, 73, 29-37.

20. Nyangena, O.; Senelwa, V.K.; Igesa, B.S. Climate Change-Urbanization Nexus: Exploring the Contribution of Urbanization on Carbon Emissions in East Africa. J. Sci. Eng. Res. 2019, 6, 158-165.

21. Zhou, Y.; Chen, M.; Tang, Z.; Mei, Z. Urbanization, Land Use Change, and Carbon Emissions: Quantitative Assessments for City-Level Carbon Emissions in Beijing-Tianjin-Hebei Region. Sustain. Cities Soc. 2021, 66, 102701. [CrossRef]

22. Romero-Lankao, P.; Dodma, D. Cities in transition: Transforming urban centers from hotbeds of GHG emissions and vulnerability to seedbeds of sustainability and resilience. Introduction and Editorial overview. Curr. Opin. Environ. Sustain. 2011, 3, 113-120. [CrossRef]

23. Mutizwamangiza, N.D.; Arimah, B.C.; Jensen, I. Cities and climate change: Global report on human settlements 2011. J. Sci. Eng. Res. 2011, 12, 25-53.

24. Friend, R.; Macclune, K. Regional Integration in the Mekong: Challenges of Urbanization and Climate Change. Inst. Soc. Environ. Transit. Int. Bangk. 2013, 12, 43-54.

25. He, C.; Zhou, L.; Ma, W.; Wang, Y. Spatial Assessment of Urban Climate Change Vulnerability during Different Urbanization Phases. Sustainability 2019, 11, 2406. [CrossRef]

26. Murray, V.; Ebi, K.L. IPCC Special Report on Managing the Risks of Extreme Events and Disasters to Advance Climate Change Adaptation (SREX). J. Epidemiol. Community Health 2012, 66, 759-760. [CrossRef] [PubMed]

27. Agrawala, S.; Conde, C.; Pulhin, J. Assessment of Adaptation Practices, Options, Constraints and Capacity. Chang. Mag. High Learn. 2007, 1, 717-743.

28. Mcgranahan, G.; Songsore, J. Wealth, health, and the urban household. Environ. Sci. Policy Sustain. Dev. 1994, 36, 4-45. [CrossRef]

29. Mcgranahan, G.; Songsor, J.; Surjadi, C. The Citizens at Risk: From Urban Sanitation to Sustainable Cities. Int. J. Sustain. High. Educ. 2001, 24, 455-456.

30. Garschagen, M.; Romero-Lankao, P. Exploring the relationships between urbanization trends and climate change vulnerability. Clim. Change 2015, 133, 37-52. [CrossRef]

31. Bian, X.; Chen, H.; Cao, G. Patterns of regional urbanization and its implications:An empirical study of the Yangtze River Delta region. Geogr. Res. 2013, 32, 2281-2291.

32. Lin, F.; Zhou, Z.-Y.; Yang, X. Experience and enlightenment on policy mechanisms for the international adaptation to climate change. Clim. Chang. Res. 2020, 5, 641-651.

33. Wang, Q. Effects of urbanisation on energy consumption in China. Energy Policy 2014, 65, 332-339. [CrossRef]

34. Ke, L.; Lin, B. Impacts of urbanization and industrialization on energy consumption $/ \mathrm{CO}_{2}$ emissions: Does the level of development matter? Renew. Sustain. Energy Rev. 2015, 52, 1107-1122.

35. ND-GAIN. Urban Adaptation Assessment Technical Document. Available online: https://gain.nd.edu/assets/293226/uaa_ technical_document.pdf (accessed on 29 April 2021).

36. Chen, C.; Noble, I.; Hellmann, J.; Coffee, J.; Chawla, N. University of Notre Dame Global Adaptation Index Country Index Technical Report. Available online: http://index.nd-gain.org:8080/documents/nd-gain_technical_document_2015.pdf (accessed on 29 April 2021).

37. IPCC. Climate Change 2014 Impacts, Adaptation and Vulnerability: Regional Aspects Cambridge; Cambridge University Press: Cambridge, UK, 2014.

38. Nagy, G.J.; Leal, F.W.; Azeiteiro, U.M.; Heimfarth, J.; Verocai, J.E.; Li, C. An Assessment of the Relationships between Extreme Weather Events, Vulnerability, and the Impacts on Human Wellbeing in Latin America. Int. J. Environ. Res. Public Health 2018, 15, 1802. [CrossRef] [PubMed]

39. Ao, A.; Go, B.; Ay, C.; Yilmaz, Y. Climate risk, culture and the COVID-19 mortality: A cross-country analysis-ScienceDirect. World Dev. 2021, 141, 105412

40. Tan, C.H.; Ho, S.B. Vulnerability and readiness of malaysian economy in the context of environment degradation. IOP Conf. Ser. Earth Environ. Sci. 2020, 505, 012036. [CrossRef]

41. Liu, M.; Liu, C.; Pei, X.; Zhang, S.; Ge, X.; Zhang, H.; Li, Y. Sustainable Risk Assessment of Resource Industry at Provincial Level in China. Sustainability 2021, 13, 4191. [CrossRef]

42. Moran, A.P. Notes on continuous stochastic phenomena. Biometrika 1950, 37, 17-23. [CrossRef] 
43. Brunsdon, C.; Fotheringham, S.; Charlton, M. Geographically Weighted Regression. J. R. Stat. Soc. Ser. D 1998, 47, 431-443. [CrossRef]

44. Wheeler, B.W.; Rigby, J.E.; Huriwai, T. Pokies and poverty: Problem gambling risk factor geography in New Zealand. Health Place 2006, 12, 86-96. [CrossRef]

45. Zhang, L.; Bi, H.; Cheng, P.; Davis, C.J. Modeling spatial variation in tree diameter-height relationships. For. Ecol. Manag. 2004, 189, 317-329. [CrossRef]

46. Fanglin, S. An Empirical Analysis on China's Provincial R\&D Knowledge Spillovers on Using GWR. J. Quant. Tech. Econ. 2007, 24, 145-153.

47. Peng, L.I.; Liu, R.Y.; Jian, L.I. Administrative Hierarchy and Resource Allocation Efficiency of Chinese City. Econ. Geogr. 2016, 36, 46-51.

48. Ma, G.; Lin, J.Y.; Cai, F.; Zhou, L. The China Miracle: Development Strategy and Economic Reform. China J. 2004, 4, 233-235.

49. Xue, H.; Cheng, X.; Zhang, Q.; Wang, H.; Zhang, B.; Qu, W.; Wang, Y. Temporal growth and spatial distribution of the fast food industry and its relationship with economic development in China-2005-2012. Prev. Med. 2017, 102, 79. [CrossRef]

50. Conlon, K.C.; Rajkovich, N.B.; White-Newsome, J.L.; Larsen, L.; O'Neill, M.S. Preventing cold-related morbidity and mortality in a changing climate. Maturitas 2011, 69, 197-202. [CrossRef] [PubMed]

51. Ciaravino, G.; Ciaravino, L.; Grimaldi, G.; Lombardi, G.; Sorvino, L.S. Risk management in flood events. In Flood Recovery, Innovation and Response; Oxford University Press: Oxford, UK, 2008.

52. Huang, H.Y.; Yin, H.Y.; Shieh, C.L.; Lai, W.C. The Reconstruction of the Processes of Compound Disasters in Siaolin Village Caused by the 2009 Typhoon Morakot. Soc. Soc. Manag. Syst. Internet J. 2012, 4, 41-48.

53. Huang, Z.; Xiao, J.; Li, B. The Route Choice of Market Integration Development in the Yangtze River Delta Region. Reform 2018, 12, 83-91.

54. Shi, P.J.; Chen, L.; Liu, H.L. Evaluation of Urbanization Coordination Degrees in Gansu Province. Appl. Mech. Mater. 2013, 295-298, 2486-2492. [CrossRef]

55. Zhu, H.; Zhang, Y.; Business, S.O. Coupled Coordination Evolution of Population Urbanization, Industry Urbanization and Land Urbanization of the Key Cities in Qinba Mountain Area. Areal Res. Dev. 2017, 36, 40-44.

56. Zhu, W.; Wang, M.; Zhang, B. The effects of urbanization on PM2.5 concentrations in China's Yangtze River Economic Belt: New evidence from spatial econometric analysis. J. Clean. Prod. 2019, 239, 118065. [CrossRef]

57. Yong-Lin, C.; Bing-Geng, X.; Xiao-Qing, L.I. Preliminary research on the relationship between changes of land use and urbanization in Changsha from 2003 to 2013. Econ. Geogr. 2015, 35, 149-154.

58. Zuur, A.F.; Ieno, E.N.; Elphick, C.S. A protocol for data exploration to avoid common statistical problems. Methods Ecol. Evol. 2010, 1, 3-14. [CrossRef]

59. Tobler, W.R. A Computer Movie Simulating Urban Growth in the Detroit Region. Econ. Geogr. 1970, 46, 234-240. [CrossRef]

60. Fernanda, C.M.; Ojeda, R.A.; Jaksic, F.M. Multi-scale patterns of habitat use by wild boar in the Monte Desert of Argentina. Basic Appl. Ecol. 2013, 14, 320-328. [CrossRef]

61. Wang, S.J.; Han, Y.D. Exploration of Urbanization in Northeast China:Its Development Status and Path. J. Northeast. Norm. Univ. 2018, 5, 92-99.

62. Zou, W.X.; Zhou, L.Q. Analysis of Regional Economic Integration:Yangtze River Delta, Pearl River Delta and Bohai Rim Region. Reform 2010, 10, 86-93.

63. Sudmeier-Rieux, K.; Paleo, U.F.; Garschagen, M.; Estrella, M.; Renaud, F.; Jaboyedoff, M. Opportunities, incentives and challenges to risk sensitive land use planning: Lessons from Nepal, Spain and Vietnam. Int. J. Disaster Risk Reduct. 2015, 14, 205-224. [CrossRef]

64. Kalafatis, S.E. When do climate change, sustainability, and economic development considerations overlap in cities? Environ. Politics 2018, 27, 115-138. [CrossRef]

65. Dell, M.; Jones, B.; Olken, B. Temperature shocks and economic growth: Evidence from the last half century. Am. Econ. J. Macroecon 2012, 4, 66-95. [CrossRef]

66. Yip, P. Social Unrest and the Poverty Problem in Hong Kong: Growth Imbalance and Sustainable Development; Springer Press: Singapore, 2021. 